\title{
Associating Disaster Deaths with Risk Profiles
}

\author{
Stanley W. Gilbert \\ Jennifer F. Helgeson \\ David H. Webb \\ Juan F. Fung \\ Anand Kandaswamy
}

This publication is available free of charge from: https://doi.org/10.6028/NIST.TN.2115

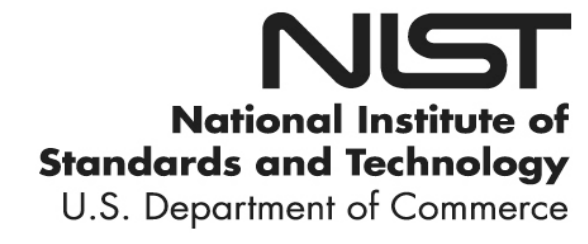




\title{
Associating Disaster Deaths with Risk Profiles
}

\author{
Stanley W. Gilbert \\ Jennifer F. Helgeson \\ David H. Webb \\ Juan F. Fung \\ Anand Kandaswamy \\ Applied Economics Office \\ Engineering Laboratory
}

This publication is available free of charge from:

https://doi.org/10.6028/NIST.TN.2115

September 2020

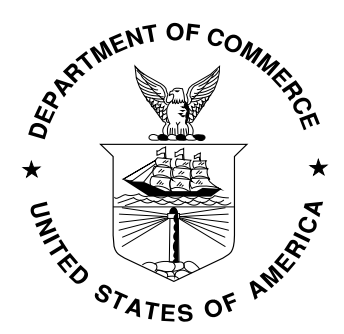

U.S. Department of Commerce

Wilbur L. Ross, Jr., Secretary

National Institute of Standards and Technology Walter Copan, NIST Director and Undersecretary of Commerce for Standards and Technology 
Certain commercial entities, equipment, or materials may be identified in this document in order to describe an experimental procedure or concept adequately. Such identification is not intended to imply recommendation or endorsement by the National Institute of Standards and Technology, nor is it intended to imply that the entities, materials, or equipment are necessarily the best available for the purpose.

National Institute of Standards and Technology Technical Note 2115 Natl. Inst. Stand. Technol. Tech. Note 2115, 35 pages (September 2020) CODEN: NTNOEF

This publication is available free of charge from: https://doi.org/10.6028/NIST.TN.2115 


\begin{abstract}
In this paper we set out to identify which "risk profiles" contribute most to deaths in disasters. A risk profile represents an identifiable group of people who would be at risk of death in a disaster through some mechanism. Four risk profiles were considered in this report, Population (representing the overall population of a location), Frailty (representing people who are in some sense physically vulnerable to injury or illness), Mobile Homes residents, and Risk Takers (proxied by the population of heavy drinkers). Overall the single greatest contributor to deaths was the "Mobile Home" risk profile, although that varied by disaster event type. The prominence of the mobile-home risk profile suggests that in many cases it proxies for a larger group, possibly related to income or educational level.

The risk profile associated with disaster fatalities depends on the type of event. For Katrinatype hurricanes and extreme-temperature events, frailty was the most important risk profile. For wind and flood events the "Mobile Home" population was overwhelmingly the most significant risk profile. For avalanche events the "Risk-Taker" profile was the most significant one. For all other event types (including non-Katrina hurricanes) fatalities were attributed to a mix of the Mobile Home and Frailty risk profiles. Disaster-related deaths do not appear to strike people at random from the population as a whole.

Looking at the county-level results, there are identifiable spatial patterns to the risk profiles. High frailty clusters tend to be found around high population regions, while high mobile home clusters are in more rural areas. Much of the U.S., spatially, is in a moderate cluster both for frailty and mobile homes, while most major population centers are part of clusters of similar values for risk profile.
\end{abstract}

\title{
Key words
}

Disaster Resilience; Disaster Deaths; Floods; Hurricanes; Katrina; Tornados; Wildland Fires. 


\section{Table of Contents}

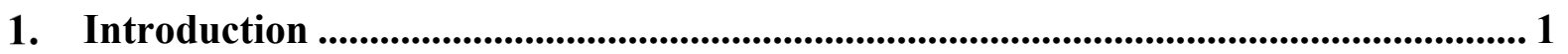

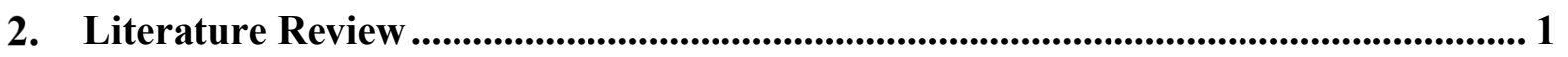

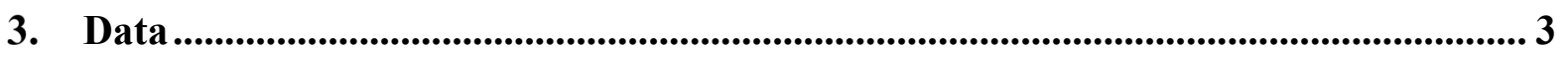

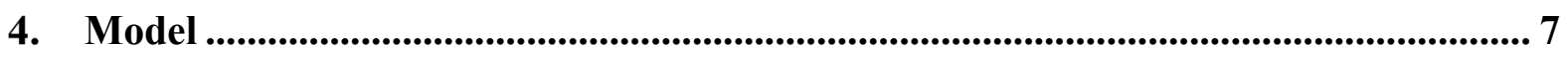

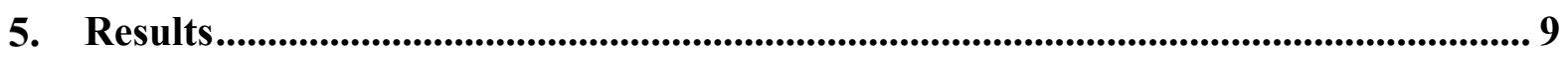

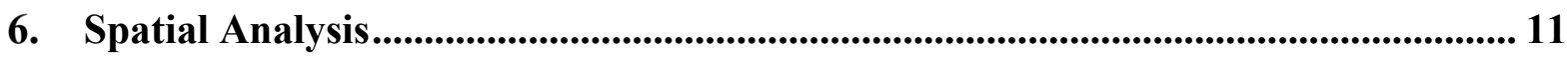

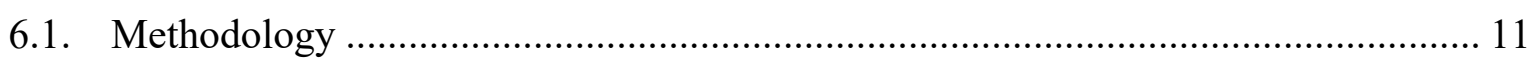

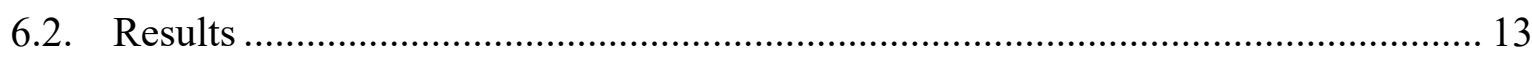

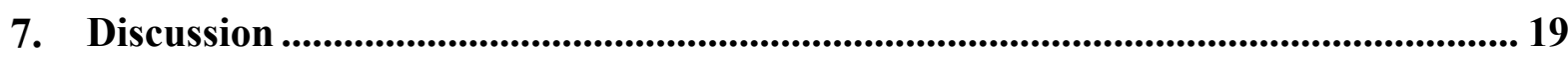

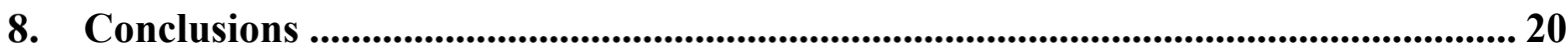

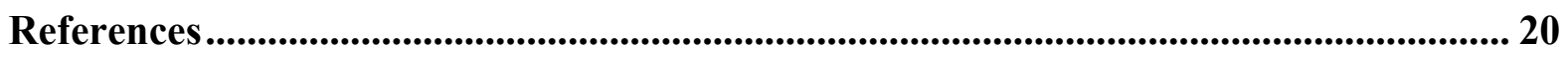

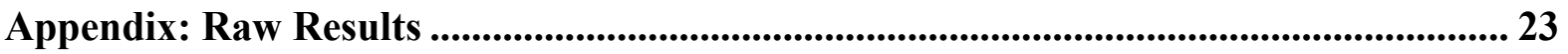




\section{List of Tables}

Table 1: Event Type crosswalk between NOAA event types and event types used in this

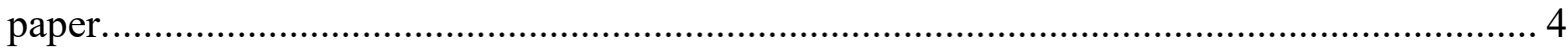

Table 2: Number of incidents excluded from the analysis and reason for exclusion............. 4

Table 3: Number of fatalities by location used in this report. ...................................... 5

Table 4: Risk profiles, their data sources, and their levels of aggregation. ......................... 6

Table 5: Correlation matrix for the risk profiles in the data set.......................................... 6

Table 6: Percent of casualties attributed to each risk profile by sex. Cluster 1 is the "Other" cluster. Cluster 2 is the "Extreme Temperature" cluster, cluster 3 is the "Wind and Flood" cluster, Cluster 4 is the "Avalanche" cluster, and Cluster 5 is the "Katrina" cluster. ............. 9

Table 7: Raw results for the average over all hazards. ................................................ 23

Table 8: Raw results for hazard deaths partitioned by location type................................ 24

Table 9: Raw results for hazard deaths partitioned by hazard type. ................................... 25

\section{List of Figures}

Figure 1: Risk profiles by age and sex for the country as a whole.

Fig. 2: Plot of percentages of attributed fatalities by sex and risk profile for each cluster for the "Avalanche", "Katrina", and "Other" clusters.

Fig. 3: Plot of percentages of attributed fatalities by sex and risk profile for each cluster for the "Extreme Temp" and "Wind and Flood" clusters.

Figure 4. Quantiles for Mortality Attributed to Mobile Home Risk Profile.......................... 13

Figure 5. U.S. Population Density by County (U.S. Census

https://www.census.gov/dmd/www/pdf/512popdn.pdf) .............................................. 14

Figure 6. Quantiles for Mortality from All Natural Hazards Attributable to Frailty ............. 15

Figure 7. Z-Score Clusters for Risk of Mortality from All Natural Hazards for the Mobile

Home risk profile ................................................................................................... 16

Figure 8. Z-Score Clusters for Percentage of Deaths due to Frailty for All Natural Disasters

Figure 9. Z-Score Hotspots for Risk of Mortality from All Natural Hazards for the Mobile Home risk profile

Figure 10. Z-Score Hotspots for Percentage of Deaths due to Frailty for All Natural Disasters 


\section{Introduction}

Since 2000 the U.S. has endured seven of the ten most costly weather disasters in its history [1]. ${ }^{1}$ While lives lost each year due to natural- and human-made disasters are trending down [2], between 2000 and 2017 more than 12000 people have died in disasters in the United States.

Knowing the intrinsic [3] characteristics of people who die in disasters would help in preventing the deaths. For example, if risk-takers form a significant fraction of the deaths in hurricanes (e.g., surfers out surfing the waves kicked up by the storm), then measures could potentially be taken to limit such behavior.

In this study we set out to identify the characteristics of people who die in disasters. We do so by identifying a set of "risk profiles"-identifiable groups of people who would be at risk of death in a disaster through different mechanisms-and estimate the percentage of deaths in different types of disasters attributable to each risk profile. To our knowledge, this study is the first to quantify the relative impact of these intrinsic characteristics on deaths in disasters.

\section{Literature Review}

Numerous studies have looked at the "intrinsic" (person-specific and physiological characteristics) and "extrinsic" (socioeconomic and location-specific factors) characteristics that contribute to deaths in natural disasters ${ }^{2}$. The risk profiles evaluated in this study are considered intrinsic characteristics.

For the purposes of this paper, studies are grouped into two types: studies that identify characteristics associated with fatalities in a specific disaster type, and studies that are primarily interested in intrinsic or extrinsic characteristics associated with disaster fatalities with less emphasis on disaster type. Studies focused on a specific disaster type are examined first.

A number of studies looked at intrinsic and extrinsic risk factors for tornado deaths. Overall, gender is not a significant factor in tornado deaths [4][5], but for some specific incidents women are at greater risk [6][7]. People over the age of 65 and under the age of 5 are overrepresented in tornado fatalities $[4][5][6][7][8][9]$.

Fatalities in tornadoes were studied for U.S. tornadoes by [4][6][7][8][9] and for a series of tornadoes in rural Bangladesh in [5]. They found that the vast majority of US fatalities occurred at home [4][8], but the majority of Bangladeshi fatalities occurred out of doors [5].

Overall, the majority of Tornado deaths in the U.S. occur in mobile homes [4][6][8]. However, during the 25 - 28 April 2011 Tornado swarm, the majority of deaths occurred in single-family dwellings [6][7], although they were unable to determine risk ratios for location.

\footnotetext{
${ }^{1}$ These NOAA data are restricted to weather disasters, and exclude disasters caused by man-made and geologic hazards

${ }^{2}$ The definitions of "Intrinsic" and "Extrinsic" characteristics used here follow Ref. [3].
} 
A number of studies looked at intrinsic and extrinsic risk factors for deaths from floods. As with tornadoes, older people are overrepresented (relative to their representation in the general population) in flood deaths [10][11][12]. The non-U.S. studies found that age groups under the age of 20 are overrepresented [11][12], while the one U.S. study found that the 1030 age groups were overrepresented. Males are also overrepresented [10][11] and in Europe are heavily overrepresented [12]. A substantial number of flood deaths are due to "risk-taking behavior" [12], primarily in vehicles driving through flood waters [10][12].

Reference [13] looked at deaths in New Orleans during Hurricane Katrina and found that the single most important factor affecting the death rate in New Orleans was age. After correcting for age, African-Americans were overrepresented among the dead. Men were over-represented compared to women, after correcting for age.

An informal look at risk factors for deadly wildfires [14], focused specifically on the 2018 Camp Fire, found, among other things, that the median age of Camp Fire victims was 72 (for comparison, the median age of Paradise, CA in the 2010 Census was 50). Among the 85 people who died, at least 62 were age 65 or older; 36 were over age 75 . Of the 85 people who died in the Camp Fire, 37 were residents of mobile homes.

Heat waves have been extensively studied (see [15] for a review). They found that people with pre-existing health issues (e.g., cardiac, lung, diabetes, chronic mental health) are more vulnerable. People over 65-years old had the largest number of excess deaths, and there is a potential for greater impact on women. Extrinsic factors that contribute to deaths are living alone and having fewer social contacts.

Some studies approached the problem from the direction of vulnerability rather than from the perspective of a specific hazard. Reference [16] reviewed the intersection of social vulnerability and climate change. They found that old age was the most significant intrinsic factor for heat-related mortality and a significant factor for flood-related mortality. Lower socioeconomic status was a significant extrinsic factor in both heat- and flood-related deaths. Females also tended to have higher rates of heat-related mortality.

Reference [17] looked specifically at age as a factor in disaster vulnerability and found that the older persons often receive less post-disaster assistance than others. They also tend to perceive themselves as having higher losses.

Reference [18] looked at frailty, specifically with regard to home fires. They found that, after accounting for "frailty" (which they defined based on the natural-causes death rate), age did not correlate with the death rate in fires in adults. That is, the correlation of death rate with age was completely accounted for by "frailty."

This is an ecological study using aggregate data to draw inferences about the impact of individual-level characteristics on risk of death in disasters. While ecological studies have a long history of providing insight into important epidemiological issues, it is well known that under certain conditions they can produce results at variance with the individual-level correlation that is actually sought [19]. As such the results of this study should be viewed as preliminary. 


\section{Data}

Data is drawn from the National Climatic Data Center's Storm Events Database ${ }^{3}$, the 2000 U.S. Census, the American Community Survey (ACS), Census Public Use Microdata Samples (PUMS), the National Survey on Drug Use and Health (NSDUH), and the CDC Wonder data set. The data consists of the array of deaths from disasters between 2000 and 2017 by county and year, sex and age, four risk profiles that will serve as the center point of this analysis, and a set of "nuisance variables."

The Storm-Events Database is the source of the event deaths. In spite of its name it covers not just meteorological events, but also includes some geologic ones. For example, avalanches and debris flows are included. The Storm-Events Database includes, among other things, the type of event and a textual description of the event. A single hazard crossed with forecast zone typically constitutes an event. However, in some cases (in particular with Tropical Storms and Hurricanes) a single hazard may be broken up into multiple events, typically on the basis of the different mechanisms by which damage or casualties occur. For example, Hurricane Wilma in Florida is associated with 17 different Episodes, spanning 49 different events with event types including (among others) Hurricane, Tropical Storm, High Wind, Tornado, Storm Surge, Heavy Rain, and High Surf.

The quality of results in this analysis for a single event type depends on the number of deaths in the database for that event type. In order to obtain more robust results, similar categories were consolidated. The categories consolidated are listed in Table 1. Table 1 also shows the number of deaths between 2000 and 2017 associated with each event. Tropical events were more difficult because they often were categorized in the database under several different (and not obviously related) event types. In order to consolidate all the tropical events under a single event type, the textual description for each event was searched. If a tropical storm/hurricane was mentioned by name in the textual description, and the storm occurred within a few days of the start of the event, it was associated with the named tropical event. Hurricane Katrina was separated out from the other tropical events based on the authors' expectation that it would be different from other tropical events. Hurricane Katrina was an extreme event both in terms of the number of deaths and in terms of the amount of damages. In fact, there are more deaths associated with Hurricane Katrina than with all the rest of the top ten disasters combined $[1]^{4}$.

The forecast zone in the Storm-Events database was used to identify counties. Forecast zones usually correspond to counties. However, in a number of cases a single forecast zone is associated with several counties. In addition, forecast zones are subject to change. The definitions of forecast zones used in this paper are from December 2017 and represent a point in time, and so a number of forecast zones were unidentifiable as to their county.

Any forecast zone that was associated with multiple counties or for which no county could be identified was excluded from the analysis. Table 2 lists the number of incidents excluded from the analysis due to association with one of these forecast zones.

\footnotetext{
${ }^{3}$ Data is downloadable from $\mathrm{ftp} / / / \mathrm{ftp} . n c d c . n o a a . g o v / p u b /$ data/swdi/stormevents/csvfiles/

${ }^{4}$ Note that the number of deaths considered here are those for the continental United States and in particular exclude Puerto Rico.
} 
Table 1: Event Type crosswalk between NOAA event types and event types used in this paper.

\begin{tabular}{|c|c|c|}
\hline Event Type & Deaths & NOAA Event Types \\
\hline Astronomical Low Tide $^{*}$ & 1 & Astronomical Low Tide \\
\hline Avalanche & 274 & Avalanche \\
\hline Blizzard & 116 & Blizzard \\
\hline Coastal Flood* & 4 & Coastal Flood \\
\hline Debris Flow & 72 & Landslide; Debris Flow \\
\hline Dense Fog & 155 & Dense Fog \\
\hline Dense Smoke* & 2 & Dense Smoke \\
\hline Dust Storm & 44 & Dust Storm \\
\hline Excessive Heat & 2215 & Heat; Excessive Heat \\
\hline Extreme Cold & 499 & Cold/Wind Chill; Extreme Cold/Wind Chill \\
\hline Flash Flood & 965 & Flash Flood \\
\hline Flood & 544 & Flood; Heavy Rain \\
\hline Freezing Fog ${ }^{*}$ & 18 & Freezing Fog \\
\hline Hail & 31 & Hail \\
\hline Heavy Snow & 164 & Lake-Effect Snow; Heavy Snow \\
\hline High Surf & 180 & High Surf \\
\hline High Wind & 181 & High Wind \\
\hline Ice Storm & 121 & Ice Storm \\
\hline Katrina & 1004 & (special, see text) \\
\hline Lakeshore Flood* & 2 & Lakeshore Flood \\
\hline Lightning & 658 & Lightning \\
\hline Rip Current & 737 & Rip Current \\
\hline Sleet ${ }^{*}$ & 2 & Sleet \\
\hline Sneakerwave $^{*}$ & 15 & Sneakerwave \\
\hline Strong Wind & 217 & Strong Wind \\
\hline Thunderstorm Wind & 511 & Thunderstorm Wind \\
\hline Tornado & 1426 & Tornado \\
\hline Tropical Events & 755 & (special, see text) \\
\hline Tsunami & 33 & Tsunami \\
\hline Waterspout ${ }^{*}$ & 5 & Waterspout \\
\hline Wildfire & 185 & Wildfire \\
\hline Winter & 1087 & Winter Weather; Winter Storm \\
\hline Not Used & 102 & $\begin{array}{l}\text { Marine Strong Wind; Marine Thunderstorm } \\
\text { Wind; Dust Devil; Marine High Wind; } \\
\text { Frost/Freeze; Marine Dense Fog; Funnel Cloud }\end{array}$ \\
\hline
\end{tabular}

This event type had too few deaths to be included in the analysis.

Table 2: Number of incidents excluded from the analysis and reason for exclusion.

\begin{tabular}{lr} 
Inclusion & Count \\
\hline Excluded - Multiple Counties & 47414 \\
Excluded - No County & 47155 \\
Included & 952045
\end{tabular}


Table 1 lists event types used in this study, with the number of deaths between 2000 and 2017 associated with each event type. The table also lists the NOAA event types that are associated with each event type used in this paper.

Reference [20] suggested that there is a distinction between disasters that are "indoors" versus those that are "outdoors." The relevance of that distinction is tested here. The expectation is that "Outdoor" disasters are more likely to strike the fit and "Indoor" disasters more likely to strike the frail. The location type information in the Storm-Events Database is used to distinguish between "Indoor" and "Outdoor" fatalities. A third category ("Water") is also distinguished. In the Storm-Events Database, deaths are categorized by the type of location where they occur. This includes locations like "Permanent Home," "Business," "Under Tree," or "In Water." "Indoor" fatalities occur either in a permanent home or mobile/trailer home. "Water" fatalities occur either in a boat or in water. All other location types are categorized as "Outdoor." Table 3 lists the locations as used in this paper and the number of deaths associated with each location.

Table 3: Number of fatalities by location used in this report.

\begin{tabular}{lr} 
Location Type & Deaths \\
\hline Indoor & 2853 \\
Outdoor & 7675 \\
Water & 1797
\end{tabular}

The 2000 U.S. Census and the ACS are used for the covariates. They are broken down by county and year. At the time of this report ACS data was available for 2007 - 2014. For the years between the 2000 Census and the start of the ACS, values were linearly interpolated. For the years after the last of the ACS, the last year of the ACS was used. There were a few counties that did not occur in the 2000 Census and appeared in the ACS. For this analysis it was simply assumed that those counties came into existence in 2007.

For the risk profiles, there was rarely enough data to be able to estimate values for each county and each year for every age and sex category. In the cases where data was not sufficient, data was grouped either geographically, over time, or both to ensure there was enough data to produce reliable estimates. In cases where estimates were made at a larger geographic or temporal unit than the one used in this study, the risk profiles were computed in proportions. That is, the proportion of people in the specific age-sex category who fit into the risk profile was computed from the original data source. That was applied to the actual population in the age-sex category for each county-year to estimate the number of people who fit each risk profile. Levels of aggregation for all risk profiles are listed in Table 4.

The Population risk profile was drawn from the Census and ACS data. It consisted of the population by age and sex for each county and year.

"Frailty" is defined the same as in Ref. [18]. It is drawn from CDC Wonder and is estimated at the state level. "Frailty" consists of the natural-causes death rate by age, sex and state. County was not used since adequate data could not be obtained at that level of detail. The 
"Frailty" for a particular county is the frailty for the state it is in. Natural causes deaths were considered to be any with ICD-10 Codes A00-R99 [21].

The Mobile-Home risk profile was drawn from the Census Bureau's Public Use Microdata Sample (PUMS) Data. For each county, the number of people living in mobile homes was estimated by sex and age. Data for mobile-home population was averaged over the entire sample time period.

Table 4: Risk profiles, their data sources, and their levels of aggregation.

\begin{tabular}{llccc} 
& & & \multicolumn{2}{c}{ Aggregation } \\
Risk Profile & Metric & Data Source & Spatial & Temporal \\
\hline Population & Population & ACS & County & Annual \\
Frailty & Natural-Causes Death Rate & CDC Wonder & State & All \\
Mobile Homes & Population Living in Mobile Homes & PUMS & County & All \\
Risk-Takers & Heavy Drinking & NSDUH & National & All
\end{tabular}

PUMS data are not necessarily organized geographically by county. Rather the Census uses Public Use Microdata Areas (PUMAs) as the basic geographic unit for the PUMS Data. In some cases, a single PUMA may include more than one county. For this work, crosswalks were used to connect PUMAs to counties. For the 2000 PUMAs, the Michigan Population Studies Center has a crosswalk that connects counties to PUMAs. The 2010 PUMAs are made up of Census tracts, and the Census Bureau has a crosswalk connecting PUMAs to their constituent Census tracts. Census tracts were then rolled up to the county level.

Risk-takers were considered to be an important category to include in this analysis. It was expected that the population of heavy drinkers would proxy for the population of risk-takers. The NSDUH was the data source for heavy drinkers. Here the data used are the national estimates by age and sex.

Table 5 shows the correlation matrix for the risk profiles in the data set. If the correlation between two risk profiles were too high, then they would be effectively indistinguishable. While some of the risk profiles are relatively highly correlated, given the size of the data set we expect that they will still be readily distinguishable. Figure 1 shows the proportion of national population by age and sex for each risk profile except the population profile which would be 1 for all subgroups.

Table 5: Correlation matrix for the risk profiles in the data set.

\begin{tabular}{l|rrrr} 
& Population & MH & Frail & Heavy \\
\hline Population & 1.00 & & & \\
Mobile Home & 0.60 & 1.00 & & \\
Frail & 0.25 & 0.17 & 1.00 & \\
Heavy (risk takers) & 0.73 & 0.41 & 0.13 & 1.00
\end{tabular}




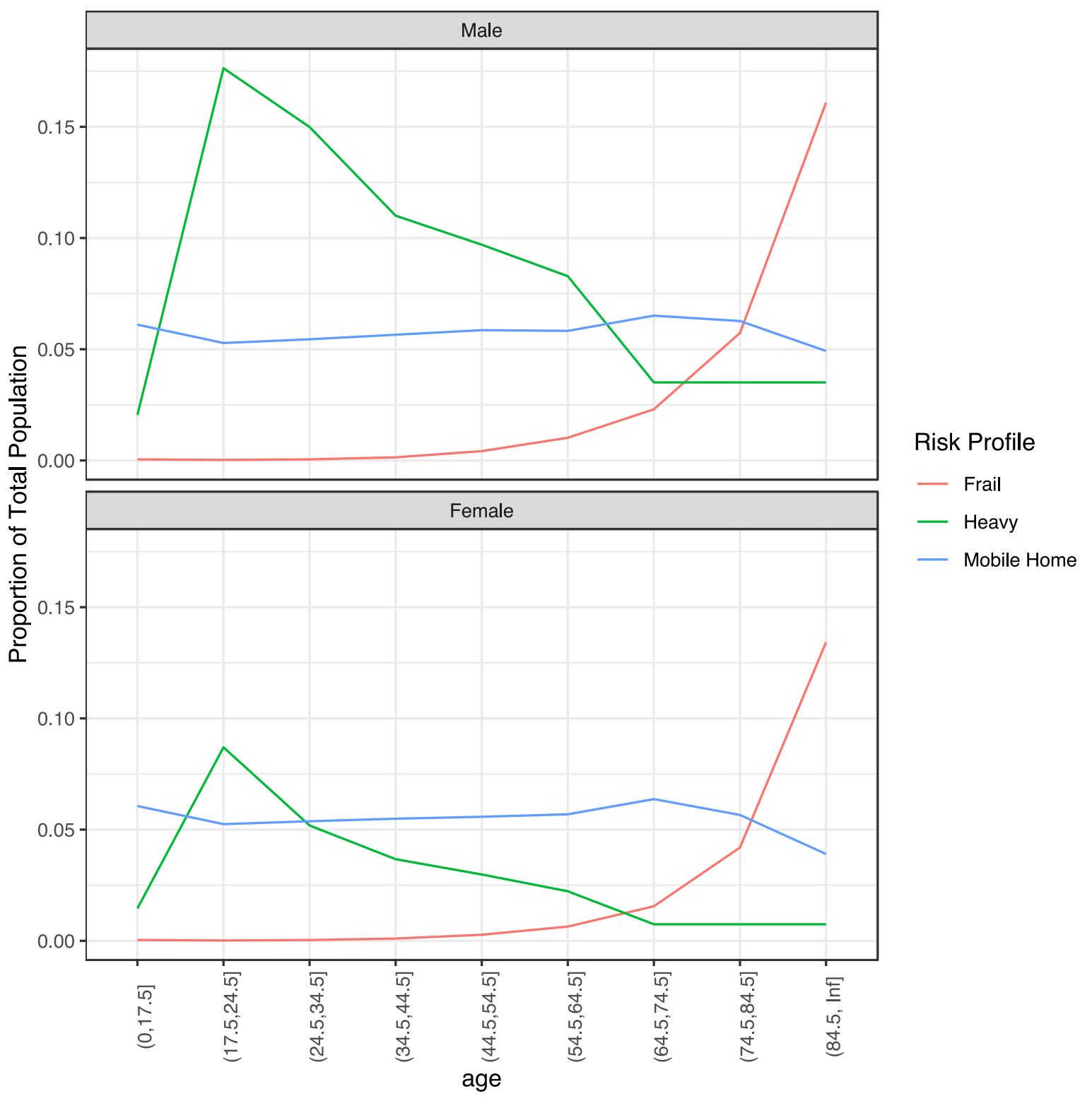

Figure 1: Risk profiles by age and sex for the country as a whole.

\section{Model}

The basic model used in this analysis is Poisson. That is, for any location $\times$ year, $i$, and $\operatorname{sex} j$ and age group $k$, the number of deaths $d_{i j k}$ is distributed as:

$$
d_{i j k} \sim \operatorname{Pois}\left(\lambda_{i j k}\right)
$$

where $\lambda_{i j k}$ is the Poisson rate parameter. 
The structure of the analysis separates out "risk profiles" from other predictors. A risk profile is a set of characteristics that can be directly associated with death in disasters. Risk profiles included in the analysis and the metrics used to measure them are listed in Table 4.

So, for example, the "Population" risk profile implies that the people who die in disasters are chosen at random from the people who live in the county, while the "Mobile Home" risk profile implies that the people who die are chosen at random from the people who live in mobile homes in the county.

The specific model was designed so that each risk profile would be independent and so that the individual contribution of each risk profile to the number of deaths could be meaningfully determined. To do that, $\lambda$ was constructed so that:

$$
\lambda_{i j k}=\sum_{m} \lambda_{i j k m}
$$

where $m$ indexes risk profiles.

The specific model used defines $\lambda$ as:

$$
\ln \left(\lambda_{i j k}\right)=\alpha_{i}+\sum_{n} \beta_{n} \cdot x_{i j k n}+\sum_{e} \tau_{e i}\left[\ln \sum_{m} \eta_{j m}^{e} \cdot y_{i j k m}\right] .
$$

In this model the notation is defined as follows:

$e$ indexes risk event types;

$\tau_{e i}$ is an indicator variable which has a value of 1 if event $\times$ location $i$ has event type $k$, and otherwise has a value of zero.

$y_{i j k m}$ is the value of the metric (e.g., population) associated with risk profile $m$.

$n$ indexes the additional variables.

$x_{i j k n}$ is the $n$th covariate in the analysis.

$a_{i}$ represent event severity for each location. The $a_{i}$ variables and the risk profiles are collinear. To address this, in implementing the model one of the $a_{i}$ terms is dropped.

$\beta_{n}$ is the coefficient associated with the nth covariate. Note that $\beta_{n}$ is common across all risk profiles. The main reason for this is to reduce the number of degrees of freedom the model is using-there just aren't that many to go around.

$\eta_{j m}^{e}$ is the coefficient associated with the $m$ th risk profile for event type $e, \operatorname{sex} j$.

Note that this structure implies that covariates (like poverty, for example) have the same impact on all risk profiles. For example, poverty will have the same impact on mortality associated with frailty as it does on mortality associated with risk-takers. While this is likely unrealistic, this is done to reduce the number of parameters estimated.

The model could not be estimated with a full set of severity terms, so they were dropped. 
Any events that have no deaths are excluded because they contribute no information to the estimation. Any event type with fewer than 25 deaths is excluded based on the assessment that any such event would have too few deaths to reliably estimate the parameters of the model for it. The model was estimated in STAN [22].

\section{Results}

Raw results are listed in the Appendix.

Table 6 shows the percent of the total deaths from each event type that are associated with each risk profile by sex. Four extra "event types" are included. The "All" composite event type represents the average contribution each risk profile makes to disaster deaths for all event types. The "Indoor," "Outdoor" and "Water" pseudo-event types are also included.

Table 6: Percent of casualties attributed to each risk profile by sex. Cluster 1 is the "Other" cluster. Cluster 2 is the "Extreme Temperature" cluster, cluster 3 is the "Wind and Flood" cluster, Cluster 4 is the "Avalanche" cluster, and Cluster 5 is the "Katrina" cluster.

Male

Female

\begin{tabular}{lrrrrrrrrr} 
Hazard & Pop & Frail & MH & Heavy & Pop & Frail & MH & Heavy & Cluster \\
\hline All & 0.2 & 20.9 & 69.6 & 9.3 & 1.0 & 27.4 & 70.1 & 1.5 & 1 \\
Indoor & 0.3 & 47.6 & 51.9 & 0.3 & 0.2 & 38.5 & 61.2 & 0.1 & 2 \\
Outdoor & 0.2 & 20.7 & 65.1 & 14.0 & 2.0 & 26.9 & 65.7 & 5.4 & 1 \\
Water & 2.0 & 0.2 & 77.0 & 20.8 & 12.7 & 1.0 & 83.0 & 3.4 & 3 \\
Avalanche & 2.0 & 0.5 & 8.0 & 89.6 & 11.7 & 4.3 & 41.6 & 42.4 & 4 \\
Blizzard & 4.2 & 35.3 & 50.9 & 9.5 & 9.4 & 6.3 & 70.3 & 14.1 & 1 \\
Debris Flow & 33.0 & 5.3 & 53.7 & 8.0 & 48.1 & 6.4 & 35.6 & 10.0 & 1 \\
Dense Fog & 6.8 & 5.8 & 48.0 & 39.5 & 17.4 & 8.8 & 65.4 & 8.4 & 1 \\
Excessive Heat & 1.2 & 48.8 & 46.0 & 3.9 & 1.0 & 65.0 & 33.7 & 0.2 & 2 \\
Extreme Cold & 1.9 & 50.1 & 36.2 & 11.7 & 2.2 & 54.9 & 40.4 & 2.5 & 2 \\
Flash Flood & 3.6 & 7.4 & 81.8 & 7.2 & 6.8 & 1.1 & 88.0 & 4.1 & 3 \\
Flood & 2.8 & 10.5 & 82.0 & 4.7 & 3.1 & 8.2 & 85.3 & 3.4 & 3 \\
Hail & 9.7 & 21.5 & 47.3 & 21.4 & 9.6 & 14.8 & 67.7 & 7.9 & 1 \\
Heavy Snow & 7.4 & 27.2 & 59.8 & 5.7 & 8.8 & 18.8 & 68.1 & 4.3 & 1 \\
High Surf & 8.2 & 3.2 & 73.3 & 15.3 & 26.5 & 7.7 & 47.2 & 18.7 & 1 \\
High Wind & 5.3 & 11.4 & 71.7 & 11.5 & 9.3 & 5.0 & 78.2 & 7.6 & 3 \\
Ice Storm & 5.5 & 21.4 & 59.7 & 13.4 & 13.9 & 12.7 & 62.0 & 11.4 & 1 \\
Katrina & 1.1 & 90.2 & 1.8 & 7.0 & 1.5 & 95.2 & 2.1 & 1.2 & 5 \\
Lightning & 1.5 & 0.4 & 71.9 & 26.2 & 6.3 & 1.2 & 80.8 & 11.7 & 3 \\
Rip Current & 2.8 & 0.2 & 78.2 & 18.8 & 26.9 & 1.1 & 67.0 & 5.0 & 3 \\
Strong Wind & 7.6 & 2.2 & 73.7 & 16.4 & 6.2 & 3.5 & 85.7 & 4.7 & 3 \\
Thunderstorm Wind & 1.9 & 6.9 & 83.2 & 8.0 & 4.0 & 3.4 & 85.5 & 7.2 & 3 \\
Tornado & 0.4 & 21.3 & 77.9 & 0.4 & 0.3 & 19.5 & 80.0 & 0.2 & 3 \\
Tropical Events & 4.4 & 19.4 & 60.8 & 15.4 & 3.3 & 28.6 & 60.9 & 7.2 & 1 \\
Wildfire & 2.3 & 20.6 & 63.9 & 13.2 & 43.3 & 18.0 & 25.8 & 12.9 & 1 \\
Winter & 1.3 & 8.8 & 72.8 & 17.2 & 2.9 & 5.6 & 75.4 & 16.1 & 3
\end{tabular}


Katrina and other Tropical Events are modeled separately. The idea is that there are two types of "Tropical Event" hazards, a "normal" type and a type represented by Hurricane Katrina.

Since the risk profiles are linearly independent in the model, the relative contribution of each risk profile to total deaths for a specific event type is determined from the following formula:

$$
\pi_{j m}^{e}=\frac{1}{N_{i}} \sum_{i} p_{i j m}^{e}
$$

where:

$$
p_{i j m}^{e}=\frac{\eta_{j m}^{e} \cdot y_{i j k m}}{\sum_{m} \eta_{j m}^{e} y_{i j k m}} .
$$

Since this was computed using a Markov Chain Monte Carlo (MCMC) method, estimates for the value of $\eta_{j m}^{e}$ exist for 10000 iterations of the MCMC algorithm. The value of $p_{i j m}^{e}$ was computed for each iteration and then averaged over all iterations.

A cluster analysis was performed on the event types to identify similar types of events. Five clusters were used for the analysis. The risk profile proportions for both sexes were used as inputs for each event type. Clusters are shown in Fig. 2 and Fig. 3.

Figures 2 and 3 gives a graphical representation of a representative hazard from each cluster. "Avalanche" is its own cluster and the deaths due to avalanche are overwhelmingly attributed to the "heavy" profile, especially among males, which suggests that they are overwhelmingly risk-takers.

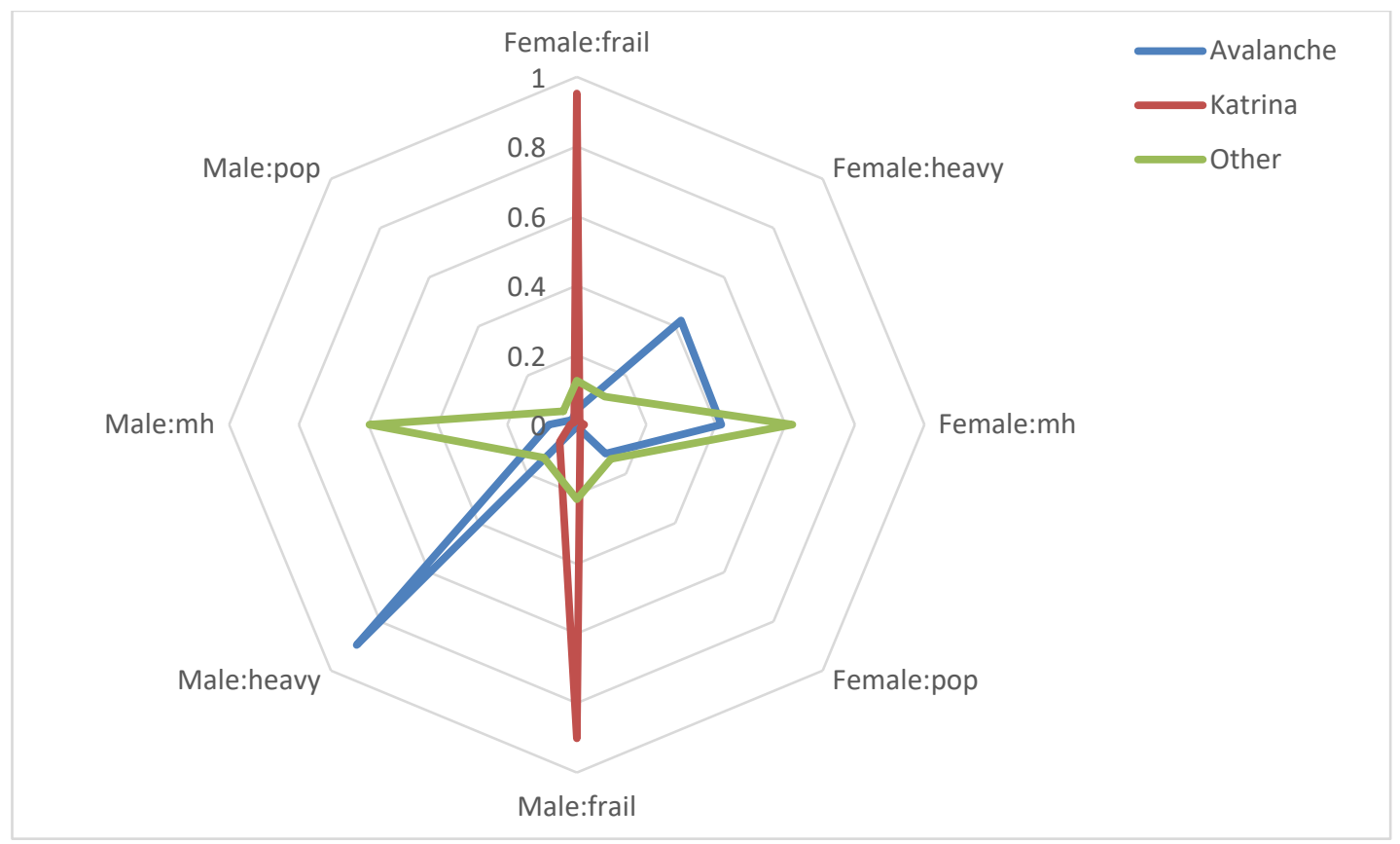

Fig. 2: Plot of percentages of attributed fatalities by sex and risk profile for each cluster for the "Avalanche", "Katrina", and "Other" clusters. 


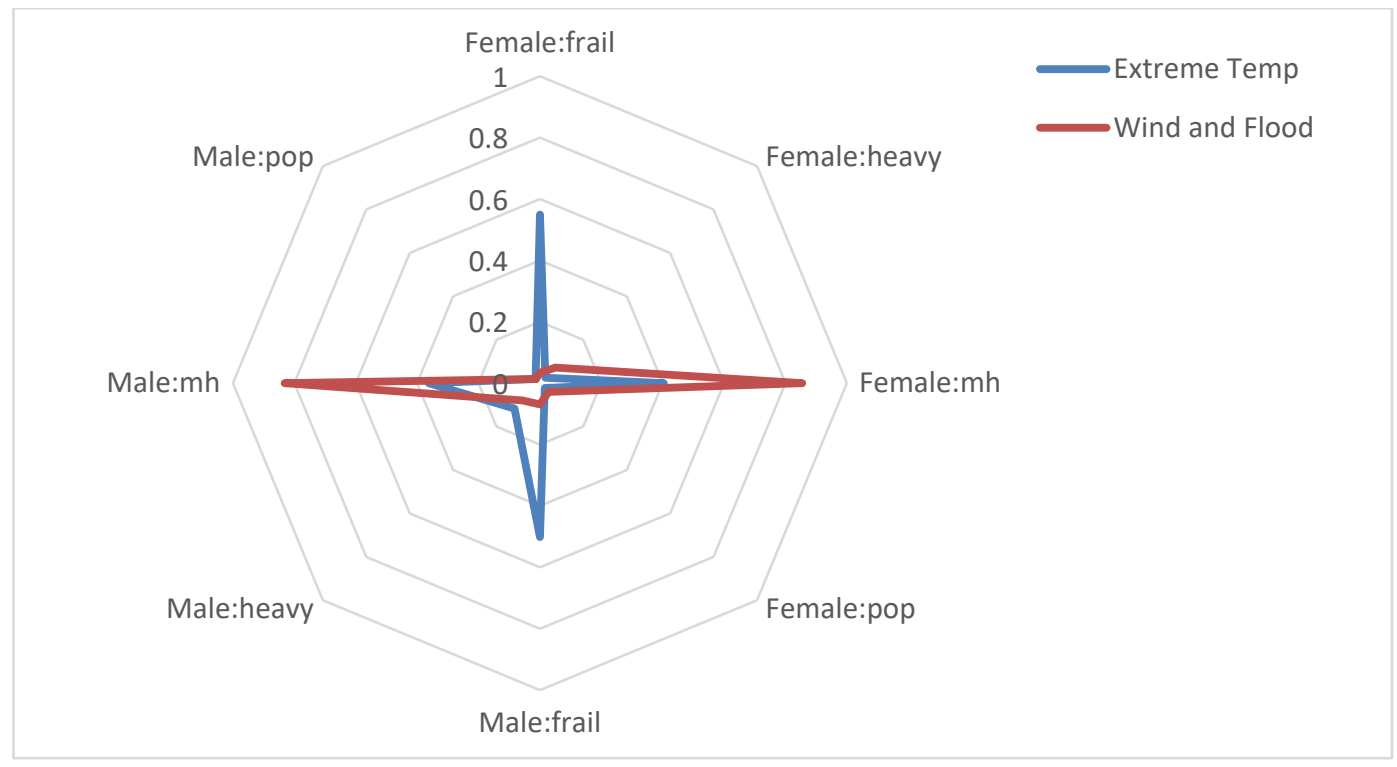

Fig. 3: Plot of percentages of attributed fatalities by sex and risk profile for each cluster for the "Extreme Temp" and "Wind and Flood" clusters.

The "Katrina" event is also its own cluster, and the deaths in Katrina are overwhelmingly attributed to the "frail" profile. That is significantly different from other Tropical Events that fall in the "Other" cluster. The "Extreme Temperature" cluster contains the "excessive heat" and "excessive cold" type events as well as the "indoor" pseudo-event. The majority of deaths for events in the "Extreme Temperature" cluster are attributed to the "frail" profile, but nearly as many deaths are attributed to the "mobile home" profile as to the "frail" profile.

The "Wind and Flood" cluster contains mostly high-wind and flooding events. In particular, this includes tornadoes. The "Water" pseudo-event also falls within this cluster. Deaths due to events in the "Wind and Flood" cluster are overwhelmingly attributed to the "Mobile Home" Profile.

The "Other" cluster contains a not-obviously-related collection of events and includes the "Outdoors" pseudo-event and the all-hazards composite event. Deaths due to events in that cluster are primarily attributed to mobile homes-but not nearly as strongly as for the "Wind and Flood" cluster-with "frail" typically being the second largest contributor.

\section{Spatial Analysis}

\subsection{Methodology}

For each county, the expected contribution of each risk profile to disaster fatalities was estimated based on the estimated model and using the most recent data available. For each county and each hazard type (or composite event types) the expected proportion of disaster fatalities associated with each risk profile is estimated. The analysis below is limited to the 
"All Disasters" composite event type. Since the bulk of the fatalities are attributed to the Mobile-Home and Frailty risk profiles for most counties, those are the risk profiles analyzed here.

The county level results provide information on what proportion of disaster fatalities are attributed to either Mobile Homes or Frailty. However, counties, while discrete political entities, often share similarities with bordering counties. Geographically there are often slow gradations as rural territories move to suburbs, then cities which expand beyond set county boundaries. As such the possibility of regional trends in risk profiles is worth considering.

Two types of analysis are conducted to check for regional trends. The first is Anselin Local Moran's I [23]. It establishes a local indicator of spatial association based on Moran's I statistic [24] with the properties that each observation is an indicator of local clustering around that observation and the sum of all local indicators is proportional to some global indicator of spatial correlation. The ultimate result is a statistic grouping similar observation values and denoting outliers.

The second analysis is the determination of hotspots using the Getis-Ord GI* [25][26]. Hotspot analysis attempts to find spatial clusters of abnormally high or low levels in spatial units relative to neighboring spatial units. It is important to note that hotspot analysis under Getis-Ord requires clustering to exist in the data. Absent any existing clusters, Getis-Ord GI* fails to provide meaningful results. The Getis-Ord GI* statistic measures the direction (region with higher values or region with lower values) of clustering as opposed to the general existence of clusters within the data.

Crucial to any clustering or hotspot analysis is the choice of how neighbors are defined for the purposes of the statistics in question. Delaunay Triangles [27][28] are used as they allow a natural neighbor weighting and are useful for an analysis with a disparate distribution of spatial features ${ }^{5}$. Since the data are aggregated and collected in administrative spatial units, row standardization is used to create relative weightings for neighbors, in lieu of absolute weighting. The use of a fixed distance is foregone as the large differences in the size of counties, especially those in the Western United States, requires a substantial distance in order to ensure the center to center distance used in any of the weightings which would induce many Eastern United States Counties to have an excessive amount of neighbors included for their analysis.

The analysis herein uses the calculated likelihood of mortality by county and attempts to identify significant clusters of risk for the contiguous United States. While data is available for Alaska and Hawaii, their remote nature relative to the rest of the U.S. complicates their spatial analysis, and so they are excluded.

\footnotetext{
${ }^{5}$ Analysis was also done by defining neighbors using contiguous borders including nodes as well as a k-nearest-neighbors analysis using eight neighbors. Row standardization was used in all cases. The results are essentially the same for the contiguous borders, while the knearest-neighbors has the same clusters but expands their covered area,
} 


\subsection{Results}

Before examining clusters, Figure 4 provides a look at the quantiles of the raw data for the "Mobile Home" risk profile for all disasters. Most of the United States (i.e., spatial area) is above the median in terms of proportion of disaster deaths attributed to mobile homes, however the areas below the median are almost exclusively regions of high population density and high density of farmland (see Figure 5 for comparison). While this comparison offers no statistical basis for conclusions, it does provide some illustrative benefit of the spatial distribution of the values of interest.

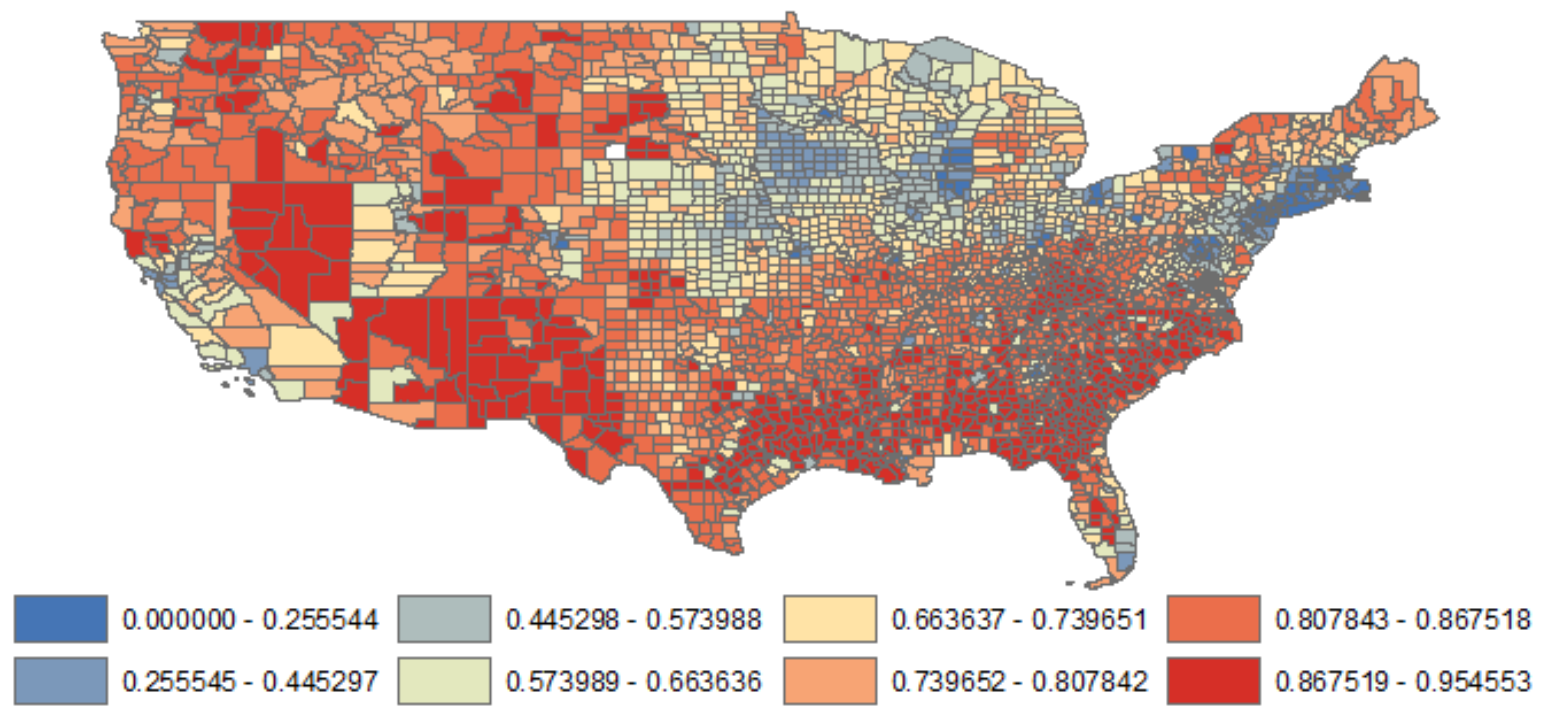

Figure 4. Quantiles for Mortality Attributed to Mobile Home Risk Profile. 


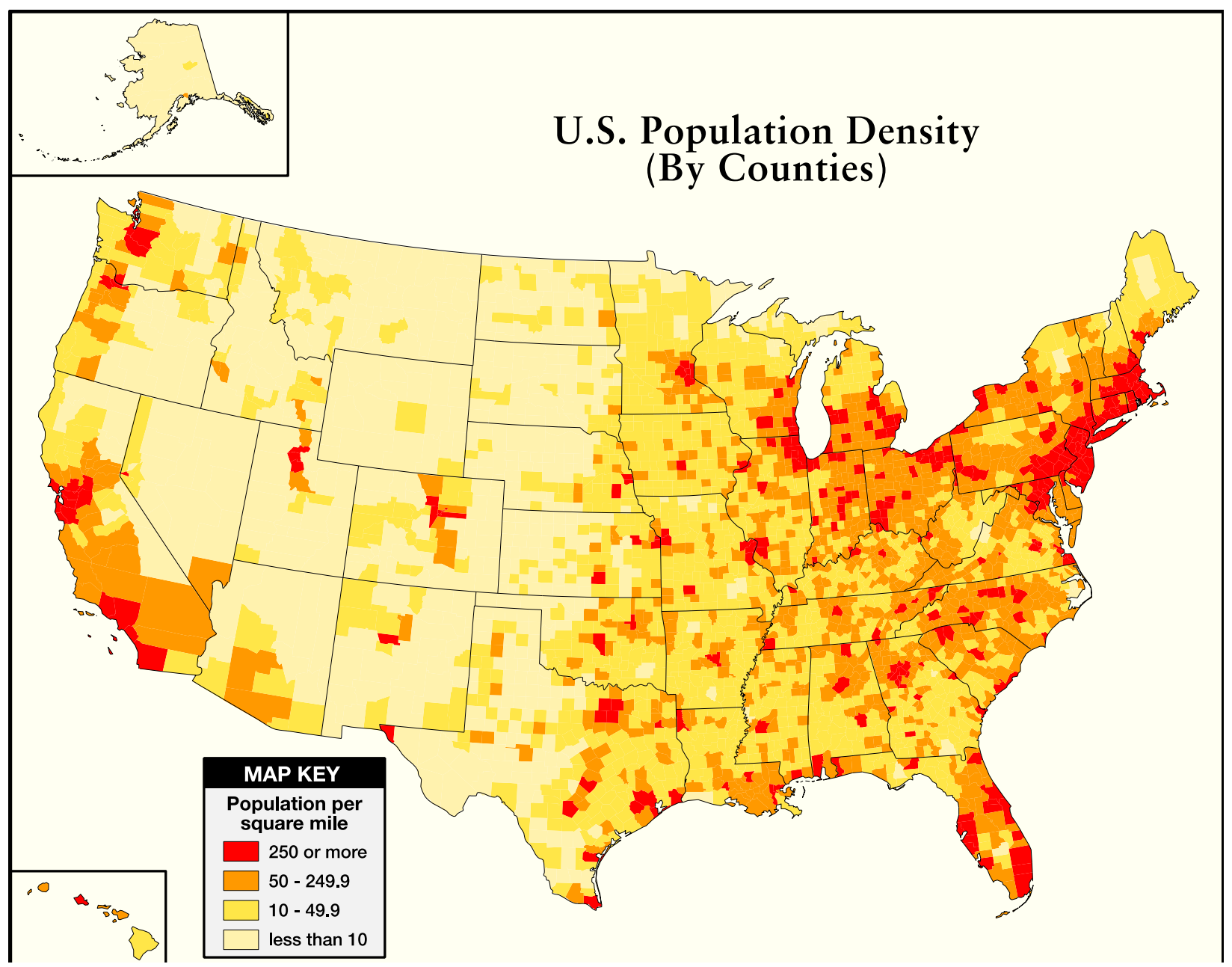

Figure 5. U.S. Population Density by County (U.S. Census https://www.census.gov/dmd/www/pdf/512popdn.pdf)

Looking now at the distribution of percentage of deaths attributed to frailty in Figure 6 , the opposite pattern emerges. This is likely due to larger population centers having fewer mobile homes resulting in the pattern in Figure 4 but a larger population, and thus a higher possibility for frailty related mortality. 


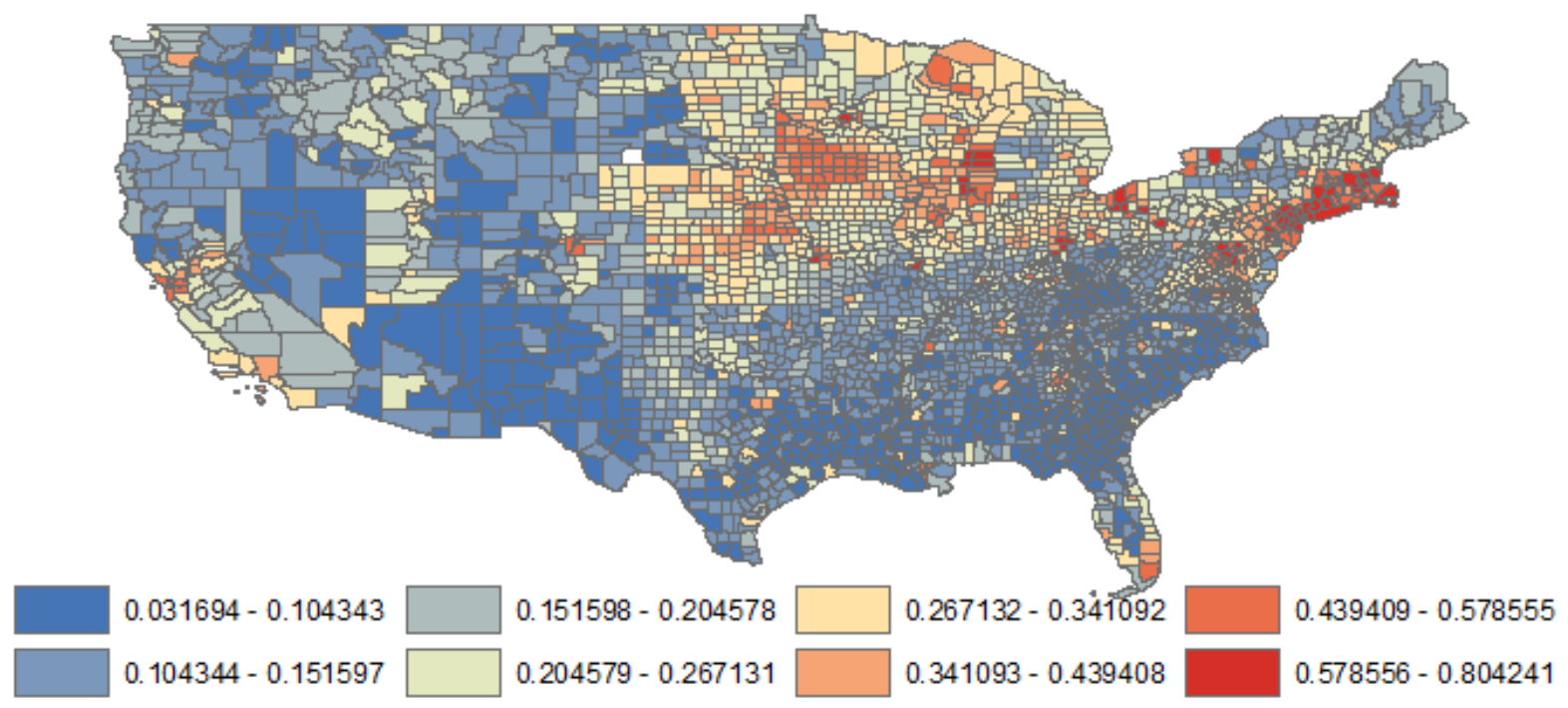

Figure 6. Quantiles for Mortality from All Natural Hazards Attributable to Frailty

The spatial clusters of counties associated with risk of mortality related to Mobile Home by county for the whole population is given in Figure 7. Counties in red have positive z-scores and are similar to their neighbors; counties in blue have negative z-scores and are outliers (spatially-dissimilar) compared to their neighbors. Thus, the groups of red counties represent positive spatial clusters. There are clusters through the Northeast corridor, north Florida into Georgia, two located in the Midwest into the Northern Great Plains and a few clusters in the West. There are also clusters around Los Angeles and the San Francisco-San Jose area. A few outliers exist sporadically, however most of the contiguous United States appears fairly uniform or have slight similarity (z-score between -2 and 2). Blue values represent negative $z$-scores and are counties that are outliers from any nearby clusters. For instance, the southern tip of Florida and the east coast of Maine. 


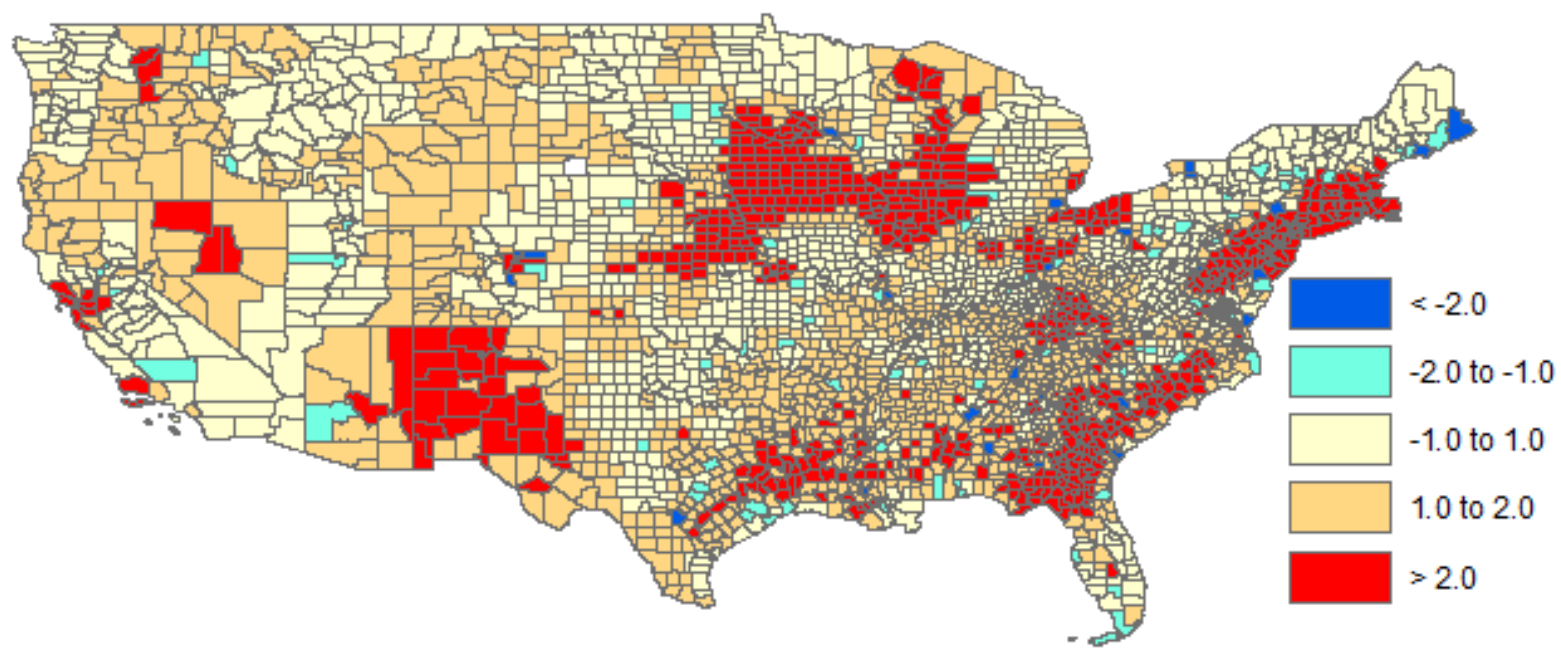

Figure 7. Z-Score Clusters for Risk of Mortality from All Natural Hazards for the Mobile Home risk profile

A few of the clusters in Figure 7 follow areas of high population density, namely the major population centers across the Northeast, the eastern shore of Lake Superior and the major cities in California. Other clusters appear near population centers, but in counties with overall low population density.

When looking at the percentage of deaths in a county due to frailty the clusters in Figure 8 emerge. Most of the clusters remain unchanged or are very similar, or increase in spatial areas, relative to the clusters in Figure 7. The cluster around Los Angeles disappears and the San Francisco cluster shrinks. 


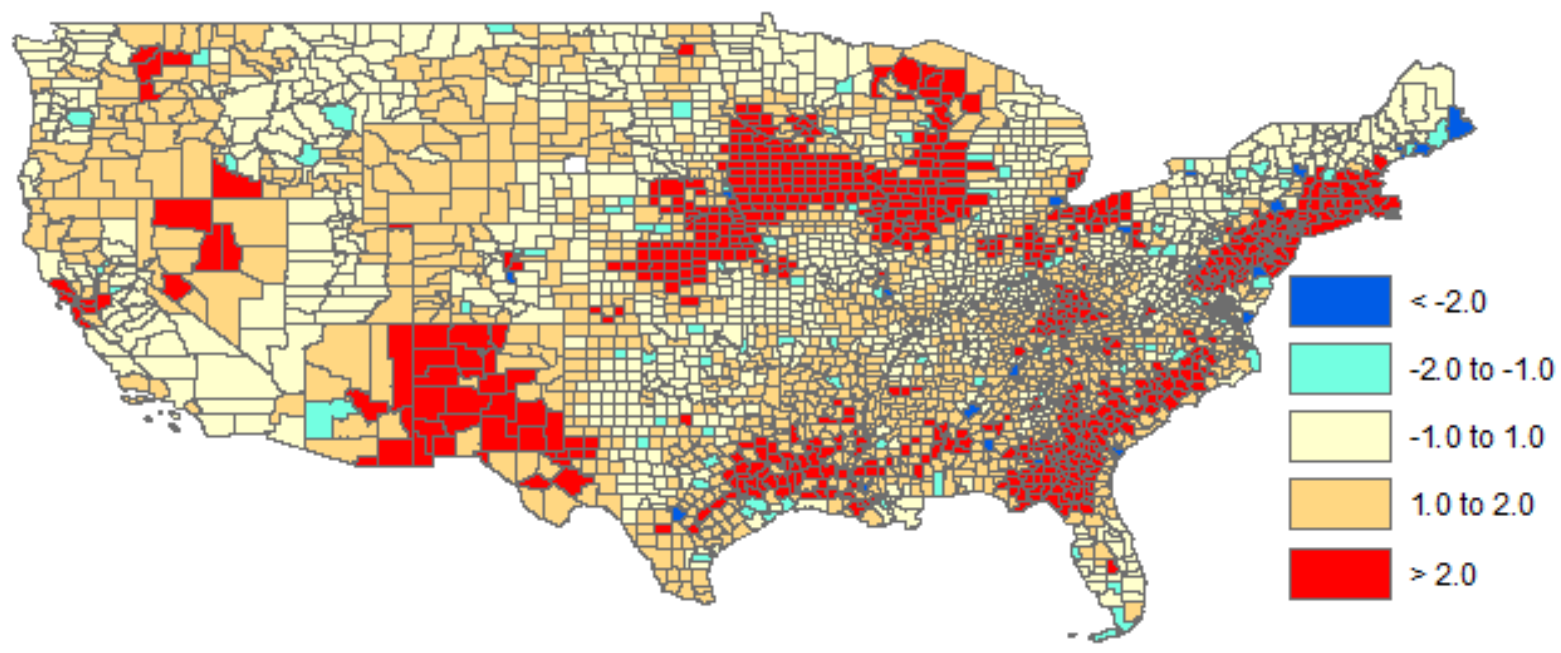

Figure 8. Z-Score Clusters for Percentage of Deaths due to Frailty for All Natural Disasters

The hotspot analysis for the Mobile Home risk profile for all natural disasters is found in Figure 9. For counties in red, deaths in disasters are more likely to be associated with mobile homes while for counties in blue they are less likely. The clusters in Figure 7 remain mostly intact. Numerous clusters in the West and South appear as cold spots and thus represent clusters of relatively high values compared to counties around them. The western cold spots contain a few counties with high population density but are mostly low-density rural counties, while the hot spots in the south traverse much of the Atlantic Coast and around the Gulf of Mexico. Atlanta clearly stands out as a cold spot, further indicating some effect due to population centers. Other population centers can also be readily picked out, including Kansas City, St. Louis, and Denver. 


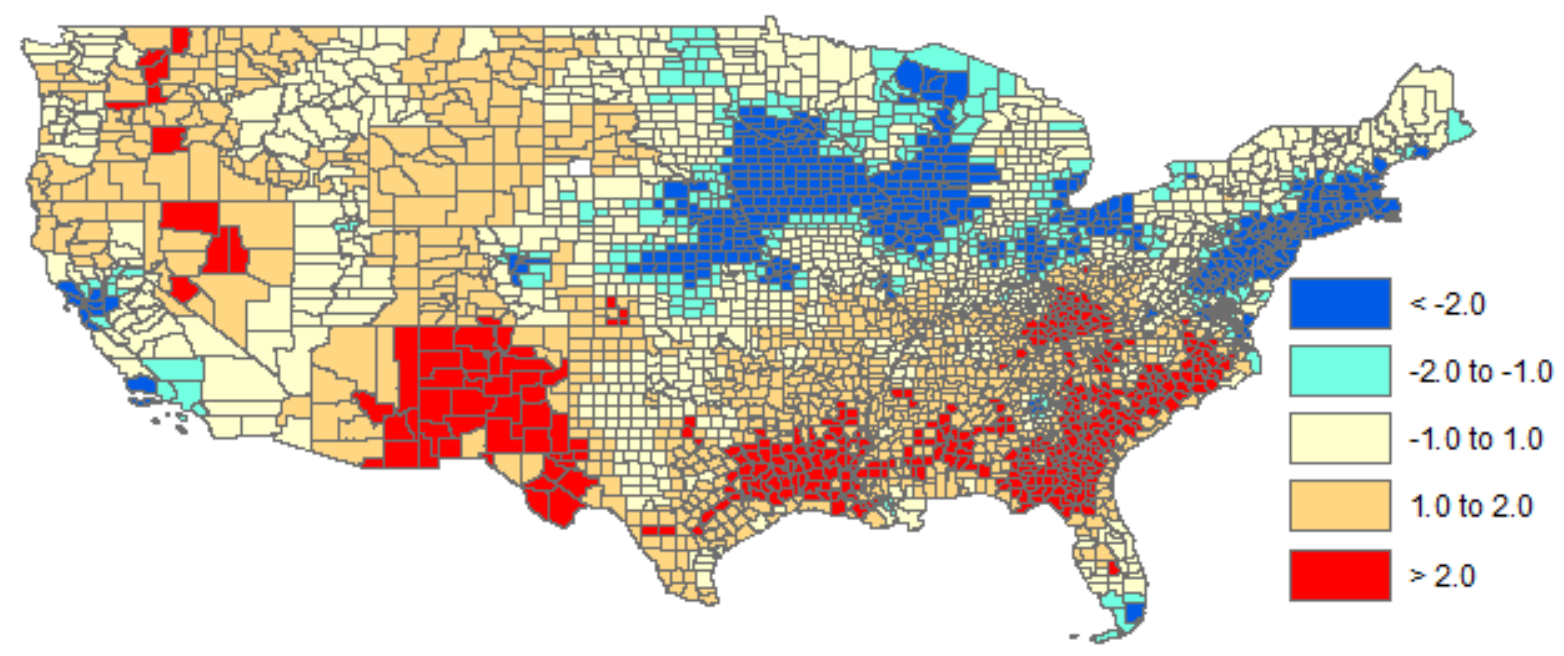

Figure 9. Z-Score Hotspots for Risk of Mortality from All Natural Hazards for the Mobile Home risk profile

As with the results for the Mobile-Home risk profile, the frailty results in Figure 10 show generally the same clusters as the corresponding cluster analysis in Figure 8, but with the regions of hot and cold spots reversed. This matches the trend in the numeric results of counties with a high value in the Mobile Home risk profile having a lower value in frailty and vice versa.

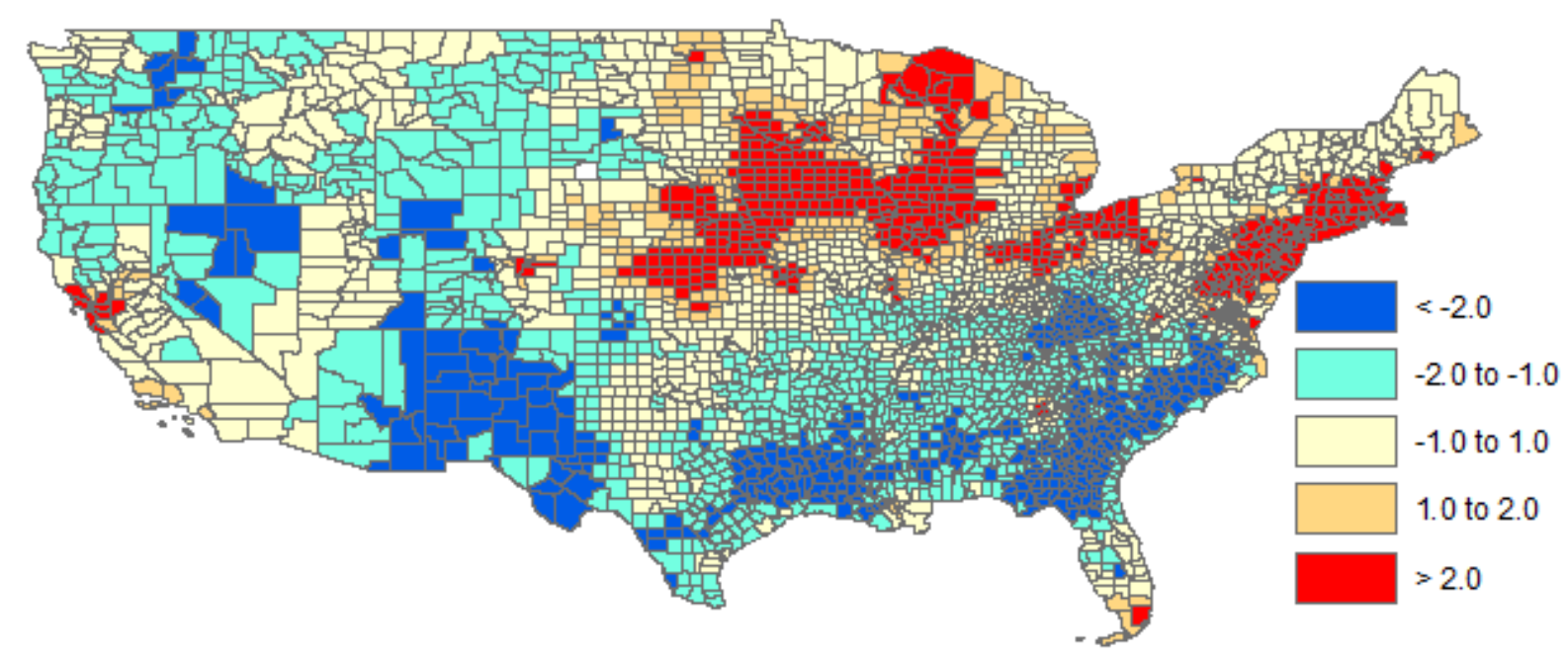

Figure 10. Z-Score Hotspots for Percentage of Deaths due to Frailty for All Natural Disasters 


\section{Discussion}

In this model the "Population" profile is almost never a significant contributor to deaths in disasters. Nearly all deaths were attributed to the other profiles. That implies that disasterrelated deaths do not strike people at random from the population as a whole.

For most disasters, deaths are not drawn from the population of risk takers (represented here by the "heavy" profile). There are a few exceptions, with Avalanche hazards being the most prominent. It is also worth noting that the assumption of this model is that deaths are drawn from the population of people living in the county where the hazard struck. For most disasters that assumption is probably reasonable, but for avalanches it may not be the case. Deaths among men are more likely to be drawn from the population of risk-takers than for women. In fact, deaths among men are more strongly associated with risk-taking than among women even after accounting for the fact that men are more likely to be accounted among the risk-taking group then women (see the raw results in the Appendix).

More generally looking at Figure 1, it is clear that men are more likely to be members of the Frail and Heavy risk profiles than women, holding age constant. That is not true of the Mobile Home cluster and (by definition) of the Population risk profile. So, all else equal, any event that works through the Frail or Heavy risk profiles will disproportionately impact men. Events like Avalanche and Lightning, with relatively high proportions of deaths attributed to "Heavy" will tend to have higher ratios of male deaths to female both because of their higher absolute risk levels (again, see the Appendix) and because men are more likely to be in the "Heavy" risk profile. On the other hand, a large proportion of Tornado deaths are attributed to the Mobile Home risk profile - which men and women are approximately equally likely to be members of - and the relative risks (from the Appendix) are approximately equal. In Katrina, men were at a higher risk of death than women[13]. Two factors contributed. First, deaths in Katrina were overwhelming attributed to Frail, which men are inherently more likely to be members of than women. Second, conditional on being frail, the risk to men was slightly greater than that to women.

The frail are important contributors to deaths for a number of disaster types, in particular for "Katrina" type hurricanes and extreme temperature events. Neither are surprising or unexpected. It seems likely that deaths from extreme temperature events are undercounted. It is possible that the uncounted deaths are correlated with the risk profiles. If so, then that would alter these results. While it was expected that Katrina would be different from other Tropical events, it is not clear why it is different. It could be attributable to some meteorological characteristic of the storm, or some geographic, demographic, or socioeconomic characteristic of the area hit. The most likely explanation is some combination of all of the above, but determining which is beyond the scope of this study.

The majority of deaths overall, and one of the largest contributors to deaths for most groups of events is the "Mobile Home" profile. For wind and flood events, again, that is not surprising. However, the extent of that contribution overall is unexpected. Given the prominence that it has overall, it seems likely that the Mobile Home profile is (in many cases at least) proxying for some closely related group. Possibilities could include groups based on educational level, income level, or some similar group. 
The results of the spatial analysis confirm that there are some spatial patterns to the risk profiles. The Mobile Home and Frailty risk profiles tend to cluster along the same regions, though mirrored in their magnitude. The fact that high frailty clusters are found to be around high population regions, while high mobile home clusters are in more rural areas is not surprising but serves as confirmation that the calculated results are in line with population and trends and regions where mobile home density is highest. Much of the country, spatially, is in a moderate cluster, while most major populations centers are part of clusters of similar values for risk profile.

\section{Conclusions}

In this report we set out to identify which risk profiles contribute most to deaths in disasters. Four risk profiles were considered in this report, Population, Frailty, Mobile Homes, and Risk Takers (proxied by heavy drinkers). Overall, the single greatest contributor to deaths was the "Mobile Home" risk profile, although that varied by event type. The prominence of the mobile-home risk profile prompted us to interpret it in many cases as proxying for a larger group, possibly related to income or educational level. The exact identification of that group is the subject of future research.

The risk profile associated with disaster fatalities depends on the type of event. For some events (i.e., Katrina-type hurricanes and extreme temperature events), frailty was the most important risk profile. For others (i.e., wind and flood events), the "Mobile Home" population was overwhelmingly the most significant risk profile. The "general population" risk profile was almost never a significant contributor.

Looking at the county-level results, there are identifiable spatial patterns to the risk profiles. High frailty clusters tend to be found around high population regions, while high mobile home clusters are in more rural areas. Much of the country, spatially, is in a moderate cluster, while most major populations centers are part of clusters of similar values for risk profile.

\section{References}

[1] NOAA National Centers for Environmental Information (NCEI) U.S. Billion-Dollar Weather and Climate Disasters (2020). https://www.ncdc.noaa.gov/billions/, DOI: $10.25921 /$ stkw-7w73

[2] Gilbert, Stanley. "Disaster Resilience: A Guide to the Literature." NIST SP. Gaithersburg, MD: NIST, 2010.

[3] Otto, Ilona M., Diana Reckien, Christopher P. O. Reyer, Rachel Marcus, Virginie Le Masson, Lindsey Jones, Andrew Norton, and Olivia Serdeczny. 2017. "Social Vulnerability to Climate Change: A Review of Concepts and Evidence.” Regional Environmental Change 17 (6): 1651-62. https://doi.org/10.1007/s10113-017-1105-9.

[4] Ashley, Walker S. 2007. "Spatial and Temporal Analysis of Tornado Fatalities in the United States: 1880-2005." Weather and Forecasting 22 (6): 1214-28

[5] Sugimoto, Jonathan D., Alain B. Labrique, Salahuddin Ahmad, Mahbubur Rashid, Abu Ahmed Shamim, Barkat Ullah, Rolf DW Klemm, Parul Christian, and Keith P. 
West Jr. 2011. "Epidemiology of Tornado Destruction in Rural Northern Bangladesh: Risk Factors for Death and Injury." Disasters 35 (2): 329-345.

[6] Brown, Sheryll, Pam Archer, Elizabeth Kruger, and Sue Mallonee. 2002. "TornadoRelated Deaths and Injuries in Oklahoma Due to the 3 May 1999 Tornadoes." Weather and Forecasting 17 (3): 343-353.

[7] Casey-Lockyer, Mary, and Centers for Disease Control and Prevention. 2012. "Tornado-Related Fatalities-five States, Southeastern United States, April 25-28, 2011." MMWR. Morbidity and Mortality Weekly Report 61 (28): 529.

[8] Ashley, Walker S., Andrew J. Krmenec, and Rick Schwantes. 2008. "Vulnerability Due to Nocturnal Tornadoes." Weather and Forecasting 23 (5): 795-807.

[9] Chiu, Cindy H., Amy H. Schnall, Caitlin E. Mertzlufft, Rebecca S. Noe, Amy F. Wolkin, Jeanne Spears, Mary Casey-Lockyer, and Sara J. Vagi. 2013. "Mortality From a Tornado Outbreak, Alabama, April 27, 2011." American Journal of Public Health 103 (8): e52-58. https://doi.org/10.2105/AJPH.2013.301291.

[10] Ashley, Sharon T., and Walker S. Ashley. 2008. "Flood Fatalities in the United States." Journal of Applied Meteorology and Climatology 47 (3): 805-818.

[11] Diakakis, M., and G. Deligiannakis. 2017. "Flood Fatalities in Greece: 1970-2010." Journal of Flood Risk Management 10 (1): 115-23. https://doi.org/10.1111/jfr3.12166.

[12] Jonkman, Sebastiaan N., and Ilan Kelman. 2005. "An Analysis of the Causes and Circumstances of Flood Disaster Deaths." Disasters 29 (1): 75-97.

[13] Sharkey, Patrick. "Survival and Death in New Orleans: An Empirical Look at the Human Impact of Katrina.” Journal of Black Studies 37, no. 4 (2007): 482-501.

[14] Larson, Pamela Ren, and Dennis Wagner. 2019. "Where Will the West's next Deadly Wildfire Strike? The Risks Are Everywhere.” USA Today, July 23, 2019. https://www.usatoday.com/in-depth/news/investigations/2019/07/22/wildfire-risksmore-than-500-spots-have-greater-hazard-than-paradise/1801629001/.

[15] Huang, Cunrui, Adrian Gerard Barnett, Xiaoming Wang, Pavla Vaneckova, Gerard FitzGerald, and Shilu Tong. 2011. "Projecting Future Heat-Related Mortality under Climate Change Scenarios: A Systematic Review." Environmental Health Perspectives 119 (12): 1681-90. https://doi.org/10.1289/ehp.1103456.

[16] Otto, Ilona M., Diana Reckien, Christopher P. O. Reyer, Rachel Marcus, Virginie Le Masson, Lindsey Jones, Andrew Norton, and Olivia Serdeczny. 2017. "Social Vulnerability to Climate Change: A Review of Concepts and Evidence." Regional Environmental Change 17 (6): 1651-62. https://doi.org/10.1007/s10113-017-1105-9.

[17] Ngo, Ehren B. 2001. "When Disasters and Age Collide: Reviewing Vulnerability of the Elderly." Natural Hazards Review 2 (2): 80-89.

[18] Gilbert, Stanley W, and David T Butry. "Identifying Vulnerable Populations to Death and Injuries from Residential Fires.” Injury Prevention 24, no. 5 (October 2018): 35864. https://doi.org/10.1136/injuryprev-2017-042343.

[19] Piantadosi, Steven, David P. Byar, and Sylvan B. Green. "The Ecological Fallacy." American Journal of Epidemiology 127, no. 5 (May 1988): 893-904. https://doi.org/10.1093/oxfordjournals.aje.a114892.

[20] Fothergill, Alice. 1998. "The Neglect of Gender in Disaster Work: An Overview of the Literature." In The Gendered Terrain of Disaster: Through Women's Eyes, edited by Elaine Enarson and Betty Morrow, 11-26. Praeger. 
[21] World Health Organisation. 1992. International Statistical Classification of Diseases and Related Health Problems, 10th Revision (ICD-10). Geneva: WHO.

[22] Bob Carpenter, Andrew Gelman, Matthew D. Hoffman, Daniel Lee, Ben Goodrich, Michael Betancourt, Marcus Brubaker, Jiqiang Guo, Peter Li, and Allen Riddell. 2017. Stan: A probabilistic programming language. Journal of Statistical Software 76(1). https://doi.org/10.18637/jss.v076.i01.

[23] Anselin, L. (1995). Local indicators of spatial association-LISA. Geographical analysis, 27(2), 93-115.

[24] Moran, P. A. (1950). Notes on continuous stochastic phenomena. Biometrika, 37(1/2), 17-23.

[25] Getis, A., \& Ord, J. K. (2010). The analysis of spatial association by use of distance statistics. In Perspectives on spatial data analysis (pp. 127-145). Springer, Berlin, Heidelberg.

[26] Ord, J. K., \& Getis, A. (2001). Testing for local spatial autocorrelation in the presence of global autocorrelation. Journal of Regional Science, 41(3), 411-432.

[27] Delaunay, B. (1934). Sur la sphere vide. Izv. Akad. Nauk SSSR, Otdelenie Matematicheskii i Estestvennyka Nauk, 7(793-800), 1-2.

[28] Chew, L. P. (1989). Constrained Delaunay triangulations. Algorithmica, 4(1-4), 97108. 


\section{Appendix: Raw Results}

Table 7: Raw results for the average over all hazards.

\begin{tabular}{lrrrrr} 
variable & estimate & std.err & $\mathrm{t}$ & $\mathrm{p}$ & flag \\
\hline total_pop & $1.4 \mathrm{E}-06$ & $1.56 \mathrm{E}-07$ & 9.162 & $0.00 \%$ & $* * *$ \\
black & $2.2 \mathrm{E}-06$ & $1.33 \mathrm{E}-07$ & 16.278 & $0.00 \%$ & $* * *$ \\
asian & $9.9 \mathrm{E}-07$ & $2.04 \mathrm{E}-07$ & 4.864 & $0.00 \%$ & $* * *$ \\
native_a & $1.4 \mathrm{E}-05$ & $1.48 \mathrm{E}-06$ & 9.685 & $0.00 \%$ & $* * *$ \\
poverty & $-6.6 \mathrm{E}-06$ & $8.58 \mathrm{E}-07$ & -7.691 & $0.00 \%$ & $* * *$ \\
households & $-5.8 \mathrm{E}-06$ & $4.58 \mathrm{E}-07$ & -12.651 & $0.00 \%$ & $* * *$ \\
vacant & $9.9 \mathrm{E}-06$ & $6.09 \mathrm{E}-07$ & 16.319 & $0.00 \%$ & $* * *$ \\
apt & $-6.9 \mathrm{E}-08$ & $1.70 \mathrm{E}-07$ & -0.405 & $68.54 \%$ & \\
mh & $-5.7 \mathrm{E}-05$ & $1.79 \mathrm{E}-06$ & -31.954 & $0.00 \%$ & $* * *$ \\
all:Female:age_sex_pop & $1.8 \mathrm{E}-07$ & $1.19 \mathrm{E}-07$ & 1.481 & $13.87 \%$ & \\
all:Female:frail & $4.3 \mathrm{E}-04$ & $1.68 \mathrm{E}-05$ & 25.382 & $0.00 \%$ & $* * *$ \\
all:Female:mh.age & $1.8 \mathrm{E}-04$ & $5.14 \mathrm{E}-06$ & 34.351 & $0.00 \%$ & $* * *$ \\
all:Female:heavy & $7.1 \mathrm{E}-06$ & $2.95 \mathrm{E}-06$ & 2.409 & $1.60 \%$ & $*$ \\
all:Male:age_sex_pop & $7.0 \mathrm{E}-08$ & $6.62 \mathrm{E}-08$ & 1.063 & $28.78 \%$ & \\
all:Male:frail & $5.9 \mathrm{E}-04$ & $2.29 \mathrm{E}-05$ & 25.821 & $0.00 \%$ & $* * *$ \\
all:Male:mh.age & $3.2 \mathrm{E}-04$ & $8.26 \mathrm{E}-06$ & 38.778 & $0.00 \%$ & $* * *$ \\
all:Male:heavy & $2.6 \mathrm{E}-05$ & $2.33 \mathrm{E}-06$ & 11.213 & $0.00 \%$ & $* * *$
\end{tabular}


Table 8: Raw results for hazard deaths partitioned by location type.

\begin{tabular}{|c|c|c|c|c|c|}
\hline variable & estimate & std.err & $\mathrm{t}$ & $\mathrm{p}$ & flag \\
\hline total_pop & $2.4 \mathrm{E}-06$ & $1.61 \mathrm{E}-07$ & 14.813 & $0.00 \%$ & \\
\hline black & $1.7 \mathrm{E}-06$ & $1.37 \mathrm{E}-07$ & 12.115 & $0.00 \%$ & $* * *$ \\
\hline asian & 8.9E-07 & $2.10 \mathrm{E}-07$ & 4.218 & $0.00 \%$ & $* * *$ \\
\hline native_a & $1.2 \mathrm{E}-05$ & $1.55 \mathrm{E}-06$ & 7.667 & $0.00 \%$ & $* * *$ \\
\hline poverty & $-8.3 \mathrm{E}-06$ & $9.10 \mathrm{E}-07$ & -9.097 & $0.00 \%$ & $* * *$ \\
\hline holds & $-9.3 \mathrm{E}-06$ & $4.65 \mathrm{E}-07$ & -19.952 & $0.00 \%$ & $* * *$ \\
\hline vacant & $9.2 \mathrm{E}-06$ & $6.25 \mathrm{E}-07$ & 14.702 & $0.00 \%$ & $* *$ \\
\hline apt & $1.6 \mathrm{E}-06$ & $1.83 \mathrm{E}-07$ & 8.965 & $0.00 \%$ & $* *$ \\
\hline $\mathrm{mh}$ & $-4.8 \mathrm{E}-05$ & $1.77 \mathrm{E}-06$ & -27.369 & $0.00 \%$ & $* * *$ \\
\hline Indoor:Female:age_sex_pop & $6.4 \mathrm{E}$ & $6.21 \mathrm{E}-08$ & 1.035 & $30.06 \%$ & \\
\hline Indoor:Female:frail & $1.0 \mathrm{E}-03$ & $5.43 \mathrm{E}-05$ & 18.835 & $0.00 \%$ & $* * *$ \\
\hline Indo & & $1.23 \mathrm{E}-05$ & 28 & $0 \%$ & $* * *$ \\
\hline Indoc & 1.6 & $1.47 \mathrm{E}-06$ & 1.069 & $28.50 \%$ & \\
\hline Indoor:M & $1.2 \mathrm{E}-07$ & $1.16 \mathrm{E}-07$ & 1.072 & $28.38 \%$ & \\
\hline Indoo & 1.5 & $6.84 \mathrm{E}-05$ & 22.492 & $0.00 \%$ & \\
\hline Indoc & $2.3 \mathrm{E}-04$ & $1.26 \mathrm{E}-05$ & 17.941 & $0.00 \%$ & $* *$ \\
\hline Male:heavy & $1.7 \mathrm{H}$ & $1.46 \mathrm{E}-06$ & 1.176 & $23.96 \%$ & \\
\hline Outd & $3.2 \mathrm{E}$ & 2.04E-07 & 1.569 & $11.67 \%$ & \\
\hline Outdoor:Fer & $3.9 \mathrm{E}-04$ & $1.97 \mathrm{E}-05$ & 19.953 & $0.00 \%$ & $* * *$ \\
\hline Outc & 1.5 & 5.99E-06 & 47 & $0.00 \%$ & $* *$ \\
\hline $\mathrm{Ou}$ & & & & $\%$ & $* * *$ \\
\hline Outc & $9.5 \mathrm{E}-08$ & $9.11 \mathrm{E}-08$ & 1.038 & $29.91 \%$ & \\
\hline Outd & $5.7 \mathrm{E}-04$ & $2.71 \mathrm{E}-05$ & 20.974 & $0.00 \%$ & $* * *$ \\
\hline age & 2.8 & $9.20 \mathrm{E}-06$ & 30.917 & $0.00 \%$ & $* * *$ \\
\hline Outd & $3.8 \mathrm{E}-05$ & $3.18 \mathrm{E}-06$ & 11.942 & $0.00 \%$ & $* * *$ \\
\hline sex_pop & 4.4E-07 & $1.89 \mathrm{E}-07$ & 2.301 & $2.14 \%$ & $*$ \\
\hline & $5.7 \mathrm{E}-06$ & 4.93E-06 & 1.151 & $24.96 \%$ & \\
\hline 1.age & $6.7 \mathrm{E}-05$ & $6.52 \mathrm{E}-06$ & 10.342 & $0.00 \%$ & $* * *$ \\
\hline Water:Female:heavy & $5.0 \mathrm{E}-06$ & $3.94 \mathrm{E}-06$ & 1.277 & $20.16 \%$ & \\
\hline Water:Male:age_sex_pop & 4.4E-07 & $3.22 \mathrm{E}-07$ & 1.353 & $17.61 \%$ & \\
\hline Water:Male:frail & 5.3E-06 & $5.06 \mathrm{E}-06$ & 1.048 & $29.48 \%$ & \\
\hline & & $1.46 \mathrm{E}-05$ & 19.738 & $0.00 \%$ & $* * *$ \\
\hline Water:Male:heavy & $3.7 \mathrm{E}-05$ & $5.36 \mathrm{E}-06$ & 6.928 & $0.00 \%$ & $* * *$ \\
\hline
\end{tabular}


Table 9: Raw results for hazard deaths partitioned by hazard type.

\begin{tabular}{|c|c|c|c|c|c|}
\hline variable & estimate & std.err & $\mathrm{t}$ & $\mathrm{p}$ & flag \\
\hline total_pop & $1.4 \mathrm{E}-06$ & $1.68 \mathrm{E}-07$ & 8.043 & $0.00 \%$ & $* * *$ \\
\hline black & $1.9 \mathrm{E}-06$ & $1.41 \mathrm{E}-07$ & 13.306 & $0.00 \%$ & $* * *$ \\
\hline asian & $1.4 \mathrm{E}-06$ & $2.08 \mathrm{E}-07$ & 6.880 & $0.00 \%$ & $* * *$ \\
\hline native_a & $1.5 \mathrm{E}-05$ & $1.67 \mathrm{E}-06$ & 8.846 & $0.00 \%$ & $* * *$ \\
\hline poverty & $-1.4 \mathrm{E}-05$ & $9.68 \mathrm{E}-07$ & -14.133 & $0.00 \%$ & $* * *$ \\
\hline households & $-5.9 \mathrm{E}-06$ & $4.91 \mathrm{E}-07$ & -12.103 & $0.00 \%$ & $* * *$ \\
\hline vacant & $1.1 \mathrm{E}-05$ & $6.76 \mathrm{E}-07$ & 16.205 & $0.00 \%$ & $* * *$ \\
\hline apt & $1.3 \mathrm{E}-06$ & $1.88 \mathrm{E}-07$ & 7.132 & $0.00 \%$ & $* * *$ \\
\hline $\mathrm{mh}$ & $-5.1 \mathrm{E}-05$ & $1.96 \mathrm{E}-06$ & -25.883 & $0.00 \%$ & $* * *$ \\
\hline Avalanche:Female:age_sex_pop & $1.7 \mathrm{E}-06$ & $1.54 \mathrm{E}-06$ & 1.082 & $27.93 \%$ & \\
\hline Avalanche:Female:frail & $9.4 \mathrm{E}-05$ & $9.20 \mathrm{E}-05$ & 1.026 & $30.49 \%$ & \\
\hline Avalanche:Female:mh.age & $5.0 \mathrm{E}-05$ & $3.20 \mathrm{E}-05$ & 1.551 & $12.09 \%$ & \\
\hline Avalanche:Female:heavy & $1.5 \mathrm{E}-04$ & $8.35 \mathrm{E}-05$ & 1.763 & $7.79 \%$ & \\
\hline Avalanche:Male:age_sex_pop & $2.6 \mathrm{E}-06$ & $2.56 \mathrm{E}-06$ & 1.015 & $31.02 \%$ & \\
\hline Avalanche:Male:frail & $8.8 \mathrm{E}-05$ & $8.83 \mathrm{E}-05$ & 0.995 & $31.97 \%$ & \\
\hline Avalanche:Male:mh.age & $8.4 \mathrm{E}-05$ & $6.20 \mathrm{E}-05$ & 1.362 & $17.33 \%$ & \\
\hline Avalanche:Male:heavy & 8.1E-04 & $8.94 \mathrm{E}-05$ & 9.019 & $0.00 \%$ & $* * *$ \\
\hline Blizzard:Female:age_sex_pop & $8.0 \mathrm{E}-07$ & $7.32 \mathrm{E}-07$ & 1.098 & $27.23 \%$ & \\
\hline Blizzard:Female:frail & $5.5 \mathrm{E}-05$ & $5.09 \mathrm{E}-05$ & 1.080 & $27.99 \%$ & \\
\hline Blizzard:Female:mh.age & $1.2 \mathrm{E}-04$ & $5.17 \mathrm{E}-05$ & 2.299 & $2.15 \%$ & $*$ \\
\hline Blizzard:Female:heavy & $3.7 \mathrm{E}-05$ & $2.88 \mathrm{E}-05$ & 1.272 & $20.35 \%$ & \\
\hline Blizzard:Male:age_sex_pop & $1.7 \mathrm{E}-06$ & $1.51 \mathrm{E}-06$ & 1.112 & $26.63 \%$ & \\
\hline Blizzard:Male:frail & $9.1 \mathrm{E}-04$ & $2.42 \mathrm{E}-04$ & 3.763 & $0.02 \%$ & $* * *$ \\
\hline Blizzard:Male:mh.age & $3.4 \mathrm{E}-04$ & $1.02 \mathrm{E}-04$ & 3.278 & $0.10 \%$ & $* *$ \\
\hline Blizzard:Male:heavy & $3.6 \mathrm{E}-05$ & $2.28 \mathrm{E}-05$ & 1.586 & $11.28 \%$ & \\
\hline Debris Flow:Female:age_sex_pop & $2.7 \mathrm{E}-05$ & $1.34 \mathrm{E}-05$ & 2.034 & $4.20 \%$ & $*$ \\
\hline Debris Flow:Female:frail & $6.5 \mathrm{E}-04$ & $5.44 \mathrm{E}-04$ & 1.197 & $23.11 \%$ & \\
\hline Debris Flow:Female:mh.age & 2.9E-04 & $2.07 \mathrm{E}-04$ & 1.392 & $16.39 \%$ & \\
\hline Debris Flow:Female:heavy & $2.5 \mathrm{E}-04$ & $2.23 \mathrm{E}-04$ & 1.133 & $25.73 \%$ & \\
\hline Debris Flow:Male:age_sex_pop & $2.8 \mathrm{E}-05$ & $1.64 \mathrm{E}-05$ & 1.720 & $8.54 \%$ & \\
\hline Debris Flow:Male:frail & $7.8 \mathrm{E}-04$ & $6.76 \mathrm{E}-04$ & 1.152 & $24.94 \%$ & \\
\hline Debris Flow:Male:mh.age & $5.6 \mathrm{E}-04$ & $2.91 \mathrm{E}-04$ & 1.923 & $5.45 \%$ & . \\
\hline Debris Flow:Male:heavy & 9.9E-05 & $8.63 \mathrm{E}-05$ & 1.150 & $25.02 \%$ & \\
\hline Dense Fog:Female:age_sex_pop & $3.4 \mathrm{E}-06$ & $2.42 \mathrm{E}-06$ & 1.401 & $16.12 \%$ & \\
\hline Dense Fog:Female:frail & 2.3E-04 & $1.92 \mathrm{E}-04$ & 1.177 & $23.92 \%$ & \\
\hline Dense Fog:Female:mh.age & $1.8 \mathrm{E}-04$ & $6.44 \mathrm{E}-05$ & 2.827 & $0.47 \%$ & $* *$ \\
\hline Dense Fog:Female:heavy & 5.9E-05 & $4.80 \mathrm{E}-05$ & 1.221 & $22.20 \%$ & \\
\hline Dense Fog:Male:age_sex_pop & $3.1 \mathrm{E}-06$ & $2.75 \mathrm{E}-06$ & 1.112 & $26.61 \%$ & \\
\hline Dense Fog:Male:frail & $2.4 \mathrm{E}-04$ & $1.66 \mathrm{E}-04$ & 1.459 & $14.46 \%$ & \\
\hline Dense Fog:Male:mh.age & $2.4 \mathrm{E}-04$ & $8.97 \mathrm{E}-05$ & 2.725 & $0.64 \%$ & $* *$ \\
\hline Dense Fog:Male:heavy & $1.4 \mathrm{E}-04$ & $5.37 \mathrm{E}-05$ & 2.597 & $0.94 \%$ & $* *$ \\
\hline Excessive Heat:Female:age_sex_pop & $1.7 \mathrm{E}-07$ & $1.34 \mathrm{E}-07$ & 1.270 & $20.40 \%$ & \\
\hline Excessive Heat:Female:frail & $9.1 \mathrm{E}-04$ & $5.00 \mathrm{E}-05$ & 18.235 & $0.00 \%$ & $* * *$ \\
\hline Excessive Heat:Female:mh.age & $7.7 \mathrm{E}-05$ & $1.00 \mathrm{E}-05$ & 7.705 & $0.00 \%$ & $* * *$ \\
\hline
\end{tabular}




\begin{tabular}{|c|c|c|c|c|c|}
\hline variable & estimate & std.err & $\mathrm{t}$ & $\mathrm{p}$ & flag \\
\hline Excessive Heat:Female:heavy & $1.4 \mathrm{E}-06$ & $1.34 \mathrm{E}-06$ & 1.024 & $30.57 \%$ & \\
\hline Excessive Heat:Male:age_sex_pop & 4.4E-07 & $3.63 \mathrm{E}-07$ & 1.213 & $22.51 \%$ & \\
\hline Excessive Heat:Male:frail & $1.4 \mathrm{E}-03$ & $7.36 \mathrm{E}-05$ & 19.174 & $0.00 \%$ & $* * *$ \\
\hline Excessive Heat:Male:mh.age & $2.5 \mathrm{E}-04$ & $2.02 \mathrm{E}-05$ & 12.353 & $0.00 \%$ & $* * *$ \\
\hline Excessive Heat:Male:heavy & $1.1 \mathrm{E}-05$ & $4.65 \mathrm{E}-06$ & 2.474 & $1.34 \%$ & $*$ \\
\hline Extreme Cold:Female:age_sex_pop & 2.3E-07 & $1.92 \mathrm{E}-07$ & 1.180 & $23.81 \%$ & \\
\hline Extreme Cold:Female:frail & 4.3E-04 & $4.99 \mathrm{E}-05$ & 8.600 & $0.00 \%$ & $* * *$ \\
\hline Extreme Cold:Female:mh.age & $7.5 \mathrm{E}-05$ & $1.56 \mathrm{E}-05$ & 4.817 & $0.00 \%$ & $* * *$ \\
\hline Extreme Cold:Female:heavy & 7.3E-06 & $5.34 \mathrm{E}-06$ & 1.369 & $17.11 \%$ & \\
\hline Extreme Cold:Male:age_sex_pop & 3.9E-07 & $3.65 \mathrm{E}-07$ & 1.076 & $28.19 \%$ & \\
\hline Extreme Cold:Male:frail & 7.3E-04 & $7.60 \mathrm{E}-05$ & 9.634 & $0.00 \%$ & $* * *$ \\
\hline Extreme Cold:Male:mh.age & 1.2E-04 & $2.40 \mathrm{E}-05$ & 4.904 & $0.00 \%$ & $* * *$ \\
\hline Extreme Cold:Male:heavy & $1.8 \mathrm{E}-05$ & $6.21 \mathrm{E}-06$ & 2.828 & $0.47 \%$ & $* *$ \\
\hline Flash Flood:Female:age_sex_pop & $1.0 \mathrm{E}-06$ & $5.97 \mathrm{E}-07$ & 1.687 & $9.16 \%$ & \\
\hline Flash Flood:Female:frail & $2.3 \mathrm{E}-05$ & $1.77 \mathrm{E}-05$ & 1.290 & $19.70 \%$ & \\
\hline Flash Flood:Female:mh.age & $1.8 \mathrm{E}-04$ & $1.39 \mathrm{E}-05$ & 12.772 & $0.00 \%$ & $* * *$ \\
\hline Flash Flood:Female:heavy & $2.0 \mathrm{E}-05$ & $1.30 \mathrm{E}-05$ & 1.547 & $12.19 \%$ & \\
\hline Flash Flood:Male:age_sex_pop & $1.0 \mathrm{E}-06$ & $7.35 \mathrm{E}-07$ & 1.384 & $16.62 \%$ & \\
\hline Flash Flood:Male:frail & $1.8 \mathrm{E}-04$ & $5.06 \mathrm{E}-05$ & 3.570 & $0.04 \%$ & $* * *$ \\
\hline Flash Flood:Male:mh.age & $2.5 \mathrm{E}-04$ & $1.66 \mathrm{E}-05$ & 15.285 & $0.00 \%$ & $* * *$ \\
\hline Flash Flood:Male:heavy & $1.8 \mathrm{E}-05$ & $7.46 \mathrm{E}-06$ & 2.441 & $1.47 \%$ & $*$ \\
\hline Flood:Female:age_sex_pop & $3.6 \mathrm{E}-07$ & $2.94 \mathrm{E}-07$ & 1.208 & $22.72 \%$ & \\
\hline Flood:Female:frail & 7.9E-05 & $3.32 \mathrm{E}-05$ & 2.382 & $1.72 \%$ & $*$ \\
\hline Flood:Female:mh.age & $1.3 \mathrm{E}-04$ & $1.46 \mathrm{E}-05$ & 8.993 & $0.00 \%$ & $* * *$ \\
\hline Flood:Female:heavy & $1.2 \mathrm{E}-05$ & $9.24 \mathrm{E}-06$ & 1.309 & $19.07 \%$ & \\
\hline Flood:Male:age_sex_pop & $7.5 \mathrm{E}-07$ & $5.62 \mathrm{E}-07$ & 1.337 & $18.11 \%$ & \\
\hline Flood:Male:frail & 2.2E-04 & $5.99 \mathrm{E}-05$ & 3.739 & $0.02 \%$ & $* * *$ \\
\hline Flood:Male:mh.age & 2.9E-04 & $2.34 \mathrm{E}-05$ & 12.367 & $0.00 \%$ & $* * *$ \\
\hline Flood:Male:heavy & $1.3 \mathrm{E}-05$ & $7.36 \mathrm{E}-06$ & 1.710 & $8.73 \%$ & . \\
\hline Hail:Female:age_sex_pop & $2.4 \mathrm{E}-06$ & $2.30 \mathrm{E}-06$ & 1.044 & $29.66 \%$ & \\
\hline Hail:Female:frail & 3.9E-04 & $3.13 \mathrm{E}-04$ & 1.260 & $20.78 \%$ & \\
\hline Hail:Female:mh.age & $1.5 \mathrm{E}-04$ & $6.53 \mathrm{E}-05$ & 2.222 & $2.63 \%$ & $*$ \\
\hline Hail:Female:heavy & $6.1 \mathrm{E}-05$ & $5.66 \mathrm{E}-05$ & 1.081 & $27.95 \%$ & \\
\hline Hail:Male:age_sex_pop & $3.5 \mathrm{E}-06$ & $3.23 \mathrm{E}-06$ & 1.087 & $27.72 \%$ & \\
\hline Hail:Male:frail & 7.2E-04 & $4.40 \mathrm{E}-04$ & 1.644 & $10.03 \%$ & \\
\hline Hail:Male:mh.age & $1.4 \mathrm{E}-04$ & $7.68 \mathrm{E}-05$ & 1.867 & $6.19 \%$ & \\
\hline Hail:Male:heavy & $7.0 \mathrm{E}-05$ & $4.56 \mathrm{E}-05$ & 1.539 & $12.38 \%$ & \\
\hline Heavy Snow:Female:age_sex_pop & $6.3 \mathrm{E}-07$ & $4.85 \mathrm{E}-07$ & 1.289 & $19.74 \%$ & \\
\hline Heavy Snow:Female:frail & $1.3 \mathrm{E}-04$ & $6.73 \mathrm{E}-05$ & 1.873 & $6.10 \%$ & \\
\hline Heavy Snow:Female:mh.age & 7.7E-05 & $2.24 \mathrm{E}-05$ & 3.431 & $0.06 \%$ & $* * *$ \\
\hline Heavy Snow:Female:heavy & $1.1 \mathrm{E}-05$ & $1.03 \mathrm{E}-05$ & 1.106 & $26.89 \%$ & \\
\hline Heavy Snow:Male:age_sex_pop & $1.7 \mathrm{E}-06$ & $1.14 \mathrm{E}-06$ & 1.466 & $14.25 \%$ & \\
\hline Heavy Snow:Male:frail & 5.2E-04 & $1.40 \mathrm{E}-04$ & 3.721 & $0.02 \%$ & $* * *$ \\
\hline Heavy Snow:Male:mh.age & $2.0 \mathrm{E}-04$ & $3.98 \mathrm{E}-05$ & 5.033 & $0.00 \%$ & $* * *$ \\
\hline Heavy Snow:Male:heavy & $1.6 \mathrm{E}-05$ & $1.16 \mathrm{E}-05$ & 1.362 & $17.34 \%$ & \\
\hline
\end{tabular}




\begin{tabular}{|c|c|c|c|c|c|}
\hline variable & estimate & std.err & $\mathrm{t}$ & $\mathrm{p}$ & flag \\
\hline High Surf:Female:age sex pop & $9.6 \mathrm{E}-07$ & $6.63 \mathrm{E}-07$ & 1.453 & $14.62 \%$ & \\
\hline High Surf:Female:frail & 4.1E-05 & $3.84 \mathrm{E}-05$ & 1.074 & $28.30 \%$ & \\
\hline High Surf:Female:mh.age & $3.8 \mathrm{E}-05$ & 2.19E-05 & 1.712 & $8.70 \%$ & \\
\hline High Surf:Female:heavy & $2.4 \mathrm{E}-05$ & $1.84 \mathrm{E}-05$ & 1.297 & $19.47 \%$ & \\
\hline High Surf:Male:age_sex_pop & $1.4 \mathrm{E}-06$ & $1.11 \mathrm{E}-06$ & 1.245 & $21.33 \%$ & \\
\hline High Surf:Male:frail & $6.7 \mathrm{E}-05$ & $5.78 \mathrm{E}-05$ & 1.164 & $24.46 \%$ & \\
\hline High Surf:Male:mh.age & 2.7E-04 & $5.54 \mathrm{E}-05$ & 4.899 & $0.00 \%$ & $* * *$ \\
\hline High Surf:Male:heavy & $2.5 \mathrm{E}-05$ & $1.52 \mathrm{E}-05$ & 1.643 & $10.03 \%$ & \\
\hline High Wind:Female:age sex pop & $5.6 \mathrm{E}-07$ & $4.36 \mathrm{E}-07$ & 1.289 & $19.74 \%$ & \\
\hline High Wind:Female:frail & $3.9 \mathrm{E}-05$ & $3.31 \mathrm{E}-05$ & 1.193 & $23.27 \%$ & \\
\hline High Wind:Female:mh.age & $1.2 \mathrm{E}-04$ & $2.50 \mathrm{E}-05$ & 4.624 & $0.00 \%$ & $* * *$ \\
\hline High Wind:Female:heavy & $1.5 \mathrm{E}-05$ & $1.22 \mathrm{E}-05$ & 1.265 & $20.58 \%$ & \\
\hline High Wind:Male:age_sex_pop & $7.6 \mathrm{E}-07$ & $6.46 \mathrm{E}-07$ & 1.172 & $24.13 \%$ & \\
\hline High Wind:Male:frail & $1.5 \mathrm{E}-04$ & $7.14 \mathrm{E}-05$ & 2.056 & $3.97 \%$ & $*$ \\
\hline High Wind:Male:mh.age & $2.1 \mathrm{E}-04$ & $3.57 \mathrm{E}-05$ & 5.873 & $0.00 \%$ & $* * *$ \\
\hline High Wind:Male:heavy & $1.5 \mathrm{E}-05$ & $9.32 \mathrm{E}-06$ & 1.658 & $9.73 \%$ & \\
\hline Ice Storm:Female:age_sex_pop & $2.2 \mathrm{E}-06$ & $1.74 \mathrm{E}-06$ & 1.262 & $20.69 \%$ & \\
\hline Ice Storm:Female:frail & $1.9 \mathrm{E}-04$ & $1.21 \mathrm{E}-04$ & 1.585 & $11.29 \%$ & \\
\hline Ice Storm:Female:mh.age & $9.6 \mathrm{E}-05$ & $3.59 \mathrm{E}-05$ & 2.678 & $0.74 \%$ & $* *$ \\
\hline Ice Storm:Female:heavy & $5.5 \mathrm{E}-05$ & 4.17E-05 & 1.329 & $18.38 \%$ & \\
\hline Ice Storm:Male:age_sex_pop & $1.8 \mathrm{E}-06$ & $1.64 \mathrm{E}-06$ & 1.099 & $27.17 \%$ & \\
\hline Ice Storm:Male:frail & $5.2 \mathrm{E}-04$ & $2.13 \mathrm{E}-04$ & 2.426 & $1.53 \%$ & $*$ \\
\hline Ice Storm:Male:mh.age & $1.7 \mathrm{E}-04$ & $5.33 \mathrm{E}-05$ & 3.112 & $0.19 \%$ & $* *$ \\
\hline Ice Storm:Male:heavy & $4.2 \mathrm{E}-05$ & $2.81 \mathrm{E}-05$ & 1.498 & $13.41 \%$ & \\
\hline Katrina:Female:age_sex_pop & $8.4 \mathrm{E}-06$ & $6.43 \mathrm{E}-06$ & 1.301 & $19.32 \%$ & \\
\hline Katrina:Female:frail & 4.3E-02 & $2.21 \mathrm{E}-03$ & 19.658 & $0.00 \%$ & $* * *$ \\
\hline Katrina:Female:mh.age & $1.1 \mathrm{E}-04$ & $8.36 \mathrm{E}-05$ & 1.309 & $19.04 \%$ & \\
\hline Katrina:Female:heavy & $2.0 \mathrm{E}-04$ & $1.46 \mathrm{E}-04$ & 1.396 & $16.27 \%$ & \\
\hline Katrina:Male:age_sex_pop & $8.1 \mathrm{E}-06$ & $7.54 \mathrm{E}-06$ & 1.078 & $28.11 \%$ & \\
\hline Katrina:Male:frail & $4.8 \mathrm{E}-02$ & $2.47 \mathrm{E}-03$ & 19.271 & $0.00 \%$ & $* * *$ \\
\hline Katrina:Male:mh.age & $1.2 \mathrm{E}-04$ & $9.33 \mathrm{E}-05$ & 1.239 & $21.52 \%$ & \\
\hline Katrina:Male:heavy & $4.0 \mathrm{E}-04$ & $1.34 \mathrm{E}-04$ & 2.957 & $0.31 \%$ & $* *$ \\
\hline Lightning:Female:age_sex_pop & $3.0 \mathrm{E}-07$ & $2.24 \mathrm{E}-07$ & 1.341 & $17.99 \%$ & \\
\hline Lightning:Female:frail & $8.2 \mathrm{E}-06$ & $7.58 \mathrm{E}-06$ & 1.083 & $27.89 \%$ & \\
\hline Lightning:Female:mh.age & 5.9E-05 & $7.45 \mathrm{E}-06$ & 7.873 & $0.00 \%$ & $* * *$ \\
\hline Lightning:Female:heavy & $1.5 \mathrm{E}-05$ & 7.33E-06 & 1.979 & $4.78 \%$ & $*$ \\
\hline Lightning:Male:age_sex_pop & $3.1 \mathrm{E}-07$ & $2.87 \mathrm{E}-07$ & 1.097 & $27.27 \%$ & \\
\hline Lightning:Male:frail & $1.1 \mathrm{E}-05$ & $9.50 \mathrm{E}-06$ & 1.112 & $26.60 \%$ & \\
\hline Lightning:Male:mh.age & $1.8 \mathrm{E}-04$ & $1.44 \mathrm{E}-05$ & 12.803 & $0.00 \%$ & $* * *$ \\
\hline Lightning:Male:heavy & $4.0 \mathrm{E}-05$ & $6.30 \mathrm{E}-06$ & 6.297 & $0.00 \%$ & $* * *$ \\
\hline Rip Current:Female:age_sex_pop & $5.4 \mathrm{E}-07$ & $2.11 \mathrm{E}-07$ & 2.554 & $1.07 \%$ & $*$ \\
\hline Rip Current:Female:frail & 4.1E-06 & $4.01 \mathrm{E}-06$ & 1.018 & $30.87 \%$ & \\
\hline Rip Current:Female:mh.age & $2.9 \mathrm{E}-05$ & $6.79 \mathrm{E}-06$ & 4.254 & $0.00 \%$ & $* * *$ \\
\hline Rip Current:Female:heavy & $5.0 \mathrm{E}-06$ & $4.33 \mathrm{E}-06$ & 1.154 & $24.84 \%$ & \\
\hline Rip Current:Male:age_sex_pop & $5.3 \mathrm{E}-07$ & 3.92E-07 & 1.363 & $17.29 \%$ & \\
\hline
\end{tabular}




\begin{tabular}{|c|c|c|c|c|c|}
\hline variable & estimate & std.err & $\mathrm{t}$ & $\mathrm{p}$ & flag \\
\hline Rip Current:Male:frail & $5.3 \mathrm{E}-06$ & $5.23 \mathrm{E}-06$ & 1.012 & $31.16 \%$ & \\
\hline Rip Current:Male:mh.age & $2.8 \mathrm{E}-04$ & $2.14 \mathrm{E}-05$ & 13.239 & $0.00 \%$ & $* * *$ \\
\hline Rip Current:Male:heavy & $3.0 \mathrm{E}-05$ & $6.90 \mathrm{E}-06$ & 4.342 & $0.00 \%$ & $* * *$ \\
\hline Strong Wind:Female:age sex pop & $4.0 \mathrm{E}-07$ & $3.31 \mathrm{E}-07$ & 1.198 & $23.10 \%$ & \\
\hline Strong Wind:Female:frail & 2.9E-05 & $2.60 \mathrm{E}-05$ & 1.128 & $25.93 \%$ & \\
\hline Strong Wind:Female:mh.age & $1.1 \mathrm{E}-04$ & $1.85 \mathrm{E}-05$ & 5.730 & $0.00 \%$ & $* * *$ \\
\hline Strong Wind:Female:heavy & $9.8 \mathrm{E}-06$ & $8.40 \mathrm{E}-06$ & 1.166 & $24.37 \%$ & \\
\hline Strong Wind:Male:age_sex_pop & $1.2 \mathrm{E}-06$ & $8.81 \mathrm{E}-07$ & 1.316 & $18.83 \%$ & \\
\hline Strong Wind:Male:frail & $4.2 \mathrm{E}-05$ & $3.37 \mathrm{E}-05$ & 1.238 & $21.57 \%$ & \\
\hline Strong Wind:Male:mh.age & $1.8 \mathrm{E}-04$ & $2.65 \mathrm{E}-05$ & 6.681 & $0.00 \%$ & $* * *$ \\
\hline Strong Wind:Male:heavy & $2.2 \mathrm{E}-05$ & $1.03 \mathrm{E}-05$ & 2.187 & $2.87 \%$ & $*$ \\
\hline Thunderstorm & $4.6 \mathrm{E}-07$ & $3.60 \mathrm{E}-07$ & 1.268 & $20.48 \%$ & \\
\hline \multicolumn{6}{|l|}{ Wind:Female:age_sex_pop } \\
\hline Thunderstorm Wind:Female:frail & $3.8 \mathrm{E}-05$ & $2.26 \mathrm{E}-05$ & 1.669 & $9.52 \%$ & . \\
\hline Thunderstorm Wind:Female:mh.age & $1.4 \mathrm{E}-04$ & $1.52 \mathrm{E}-05$ & 9.497 & $0.00 \%$ & $* * *$ \\
\hline Thunderstorm Wind:Female:heavy & $2.1 \mathrm{E}-05$ & $1.15 \mathrm{E}-05$ & 1.828 & $6.75 \%$ & \\
\hline Thunderstorm Wind:Male:age_sex_pop & 4.3E-07 & $3.84 \mathrm{E}-07$ & 1.108 & $26.77 \%$ & \\
\hline Thunderstorm Wind:Male:frail & $1.2 \mathrm{E}-04$ & $4.15 \mathrm{E}-05$ & 2.830 & $0.47 \%$ & $* *$ \\
\hline Thunderstorm Wind:Male:mh.age & $2.4 \mathrm{E}-04$ & $1.97 \mathrm{E}-05$ & 12.340 & $0.00 \%$ & $* * *$ \\
\hline Thunderstorm Wind:Male:heavy & $1.4 \mathrm{E}-05$ & $6.10 \mathrm{E}-06$ & 2.300 & $2.15 \%$ & $*$ \\
\hline Tornado:Female:age_sex_pop & $2.9 \mathrm{E}-07$ & $2.85 \mathrm{E}-07$ & 1.021 & $30.71 \%$ & \\
\hline Tornado:Female:frail & $1.2 \mathrm{E}-03$ & $1.49 \mathrm{E}-04$ & 8.360 & $0.00 \%$ & $* * *$ \\
\hline Tornado:Female:mh.age & $5.4 \mathrm{E}-04$ & $2.77 \mathrm{E}-05$ & 19.531 & $0.00 \%$ & $* * *$ \\
\hline Tornado:Female:heavy & 7.3E-06 & $6.97 \mathrm{E}-06$ & 1.046 & $29.55 \%$ & \\
\hline Tornado:Male:age_sex_pop & $3.8 \mathrm{E}-07$ & $3.65 \mathrm{E}-07$ & 1.045 & $29.58 \%$ & \\
\hline Tornado:Male:frail & $1.3 \mathrm{E}-03$ & $1.53 \mathrm{E}-04$ & 8.747 & $0.00 \%$ & $* * *$ \\
\hline Tornado:Male:mh.age & $5.0 \mathrm{E}-04$ & $2.71 \mathrm{E}-05$ & 18.562 & $0.00 \%$ & $* * *$ \\
\hline Tornado:Male:heavy & 4.7E-06 & 4.29E-06 & 1.102 & $27.03 \%$ & \\
\hline Tropical Events:Female:age_sex_pop & $3.8 \mathrm{E}-07$ & $3.11 \mathrm{E}-07$ & 1.210 & $22.61 \%$ & \\
\hline Tropical Events:Female:frail & $2.5 \mathrm{E}-04$ & 4.17E-05 & 6.011 & $0.00 \%$ & $* * *$ \\
\hline Tropical Events:Female:mh.age & $9.3 \mathrm{E}-05$ & $1.31 \mathrm{E}-05$ & 7.092 & $0.00 \%$ & $* * *$ \\
\hline Tropical Events:Female:heavy & $2.0 \mathrm{E}-05$ & $9.34 \mathrm{E}-06$ & 2.132 & $3.30 \%$ & $*$ \\
\hline Tropical Events:Male:age_sex_pop & $1.0 \mathrm{E}-06$ & $7.53 \mathrm{E}-07$ & 1.388 & $16.51 \%$ & \\
\hline Tropical Events:Male:frail & 3.7E-04 & $6.08 \mathrm{E}-05$ & 6.116 & $0.00 \%$ & $* * *$ \\
\hline Tropical Events:Male:mh.age & $2.1 \mathrm{E}-04$ & $2.11 \mathrm{E}-05$ & 10.037 & $0.00 \%$ & $* * *$ \\
\hline Tropical Events:Male:heavy & $3.2 \mathrm{E}-05$ & $9.22 \mathrm{E}-06$ & 3.432 & $0.06 \%$ & $* * *$ \\
\hline Wildfire:Female:age_sex_pop & $7.5 \mathrm{E}-06$ & $3.68 \mathrm{E}-06$ & 2.031 & $4.22 \%$ & $*$ \\
\hline Wildfire:Female:frail & 4.3E-04 & $2.80 \mathrm{E}-04$ & 1.544 & $12.27 \%$ & \\
\hline Wildfire:Female:mh.age & $5.7 \mathrm{E}-05$ & $4.08 \mathrm{E}-05$ & 1.395 & $16.30 \%$ & \\
\hline Wildfire:Female:heavy & $9.5 \mathrm{E}-05$ & 7.53E-05 & 1.267 & $20.52 \%$ & \\
\hline Wildfire:Male:age_sex_pop & $2.2 \mathrm{E}-06$ & $2.20 \mathrm{E}-06$ & 1.005 & $31.51 \%$ & \\
\hline Wildfire:Male:frail & $1.4 \mathrm{E}-03$ & $4.62 \mathrm{E}-04$ & 3.039 & $0.24 \%$ & $* *$ \\
\hline Wildfire:Male:mh.age & 4.3E-04 & $9.67 \mathrm{E}-05$ & 4.476 & $0.00 \%$ & $* * *$ \\
\hline Wildfire:Male:heavy & $1.0 \mathrm{E}-04$ & $5.69 \mathrm{E}-05$ & 1.825 & $6.79 \%$ & \\
\hline Winter:Female:age_sex_pop & 4.6E-07 & $3.66 \mathrm{E}-07$ & 1.263 & $20.64 \%$ & \\
\hline
\end{tabular}


variable

Winter:Female:frail

Winter:Female:mh.age

Winter:Female:heavy

Winter:Male:age_sex_pop

Winter:Male:frail

Winter:Male:mh.age

Winter:Male:heavy estimate std.err

7.1E-05 2.44E-05

$1.8 \mathrm{E}-04 \quad 1.53 \mathrm{E}-05$

5.6E-05 1.41E-05

3.3E-07 3.10E-07

$1.6 \mathrm{E}-04 \quad 3.83 \mathrm{E}-05$

$2.5 \mathrm{E}-04 \quad 1.96 \mathrm{E}-05$

$3.1 \mathrm{E}-05$

$6.79 \mathrm{E}-06$

\begin{tabular}{rrr} 
& & \\
$\mathrm{t}$ & $\mathrm{p}$ & flag \\
\hline 2.906 & $0.37 \%$ & $* *$
\end{tabular}

$11.984 \quad 0.00 \% \quad * * *$

$3.9620 .01 \% * * *$

$1.06528 .69 \%$

$4.088 \quad 0.00 \% \quad * * *$

$12.638 \quad 0.00 \% \quad * * *$

$4.5810 .00 \% \quad * * *$ 